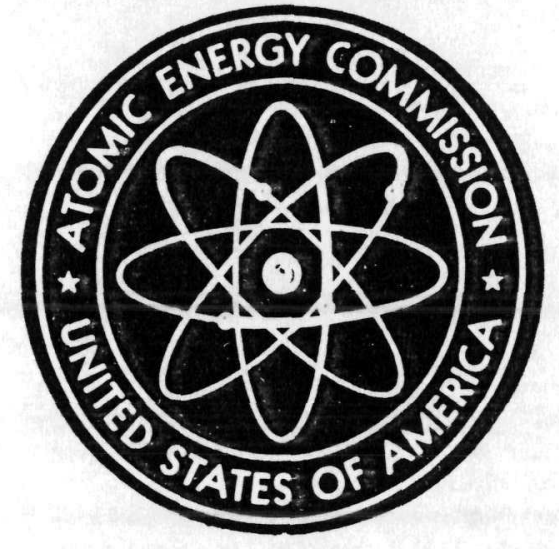

AECU-262

\title{
STATISTICAL METHODS USED IN THE MEASUREMENT OF RADIOACTIVITY WITH SOME USEFUL GRAPHS AND NOMOGRAPHS
}

By

Alan A. Jarrett

June 17,1946

Oak Ridge National Laboratory

Oak Ridge, Tennessee

UNITED STATES ATOMIC ENERGY COMMISSION • TECHNICAL INFORMATION CENTER 


\section{DISCLAIMER}

This report was prepared as an account of work sponsored by an agency of the United States Government. Neither the United States Government nor any agency Thereof, nor any of their employees, makes any warranty, express or implied, or assumes any legal liability or responsibility for the accuracy, completeness, or usefulness of any information, apparatus, product, or process disclosed, or represents that its use would not infringe privately owned rights. Reference herein to any specific commercial product, process, or service by trade name, trademark, manufacturer, or otherwise does not necessarily constitute or imply its endorsement, recommendation, or favoring by the United States Government or any agency thereof. The views and opinions of authors expressed herein do not necessarily state or reflect those of the United States Government or any agency thereof. 


\section{DISCLAIMER}

Portions of this document may be illegible in electronic image products. Images are produced from the best available original document. 
Other issues of this report may bear the number MonP-126.

\section{LEGAL NOTICE}

This report was prepared as an account of Government sponsored work. Nelther the United States, nor the Commission, nor any person scting on behalf of the Commisaton:

A. Makes any warranty or representation, expressed or Implled, with respect to the accuracy, completeness, or usefulness of the Information contained in thil report, or that the use of any information, apparatus, method, or process disclosed in this report may not infringe privately owned rights; or

B. Assumes any llabilities with respect to the use of, or for damages resulting from the use of any information, apparatus, method, or process disclosed in thls report.

As used in the above, "person acting on beball of the Commisulon" Includes any em. ployee or contractor of the Commission, or employee of such contractor, to the extent that such employee or contractor of the Commission, or employee of euch contractor preparee, disseminates, or provides access to, any information pursuant to his employment or contract with the Commission, or his employment with such contractor.

This report has been reproduced directly from the best avallable copy.

Printed in USA. Price $\$ 1.25$. Avallable from the Office of Technical Services, Department of Commerce, Washington 25 , D. C. 
TABIE OF CONTENTS

Page

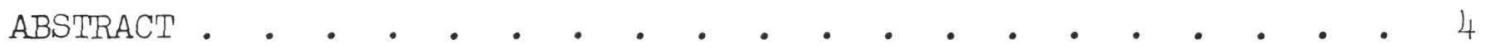

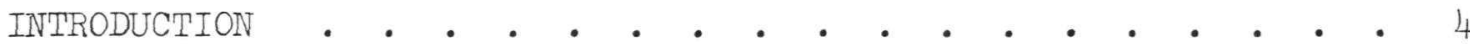

THE ERRORS OF COUNTING DETERMINATIONS • • • • • • • • • • 5

THE ERRORS IN COUNTING RATE DETERMINATIONS . • • • • • • • • 12

THE ERROR INTRODUCED BY THE BACKGROUND • • • • • • • • • • 17

THE ERROR OF THE PRODUCT OR QUOTIENT OF A SERIES OF

COUNTING RATE DETERMINATIONS • • • • • • • • • • • • • • • 24

THE ERROR IN THE SUM OF A SERIES OF COUNTING DETERMINATIONS • • • 26

THE ERROR IN THE MEAN OF A SERIES OF COUNTING DETERMINATIONS • • 28

THE ERROR IN A RESULT COMPUIED FROM ANY FUNCTION OF DIRECTLY

MEASURED QUANTITIES • • • • • • • • • • • • • • • • • • • 29

MINIMIZING THE ERROR INTRODUCED BY THE BACKGROUND BY THE

EFFICIENT DISTRIBUTION OF COUNTING TIMES

DETERMINATION OF NON-STATISTICAL COUNTER BEHAVIOR • • • • • • 34

REJECTION OF SUSPECTED OBSERVATIONS • • • • • • • • • • • 4 • 4

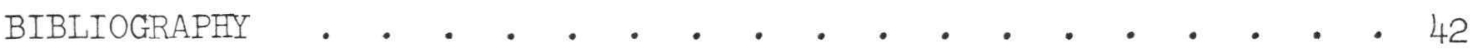

AECU-262 
STATISTICAL METHODS USED IN THE MEASUREMENT OF RADIOACTIVITY WITH SOME USEFUL GRAPHS AND NOMOGRAPHS

By Alan A. Jarrett

\section{ABSTRACT}

The statistical aspects of radioactive counting are discussed with reference to:

1. Estimation of the accuracy of counting rate determinations.

2. Description of counting procedures which will minimize errors due to the random variations in the radioactive disintegration rate.

Tables and graphs have been prepared as aids to the calculation of the magnitude of these variations and are included in the report.

In addition to the fluctuations expected in the counting rate of a radioactive sample due to the random nature of the disintegration process, there are other variables affecting the counting rate determination. Methods of determining the presence of this additional error are described.

\section{INTRODUCTION}

The improvement of radioanalytical techniques has led to more complete utilization of the information available from the laws of probability in order to correctly interpret results obtained by counting methods and also to increase the accuracy of counting rate determinations. It is because of the fact that individual nuclear disintegrations are independent of one another and nuclei disintegrate randomly that the laws of probability can be applied.

This report intends to describe the statistical aspects of counting with reference to:

1. Estimation of the accuracy of counting determinations.

2. Description of counting procedures which will minimize errors due to the random nature of the radioactive disintegration process.

It has been written in the nature of a handbook of the methods most frequently used for the statistical interpretation of counting data and contains tables and graphs as aids to the calculation of statistical 
constants. An attempt has been made to keep all theoretical considerations to a minimum compatible with an understanding of the practical applications.

In addition to the fluctuations expected in the counting rate of a radioactive sample due to the random nature of the disintegration process, there are other variables affecting the counting rate which tend to increase the actual error made in a counting rate determination. Methods of determining the presence of this additional error are described in the last section of this report. An investigation of the sources of these other variations and the statistical methods used in their investigation wili be described in subsequent reports.

\section{THE ERRORS OF COUNTING DETERMINATIONS}

In addition to the continuous decrease in the average emission rate of a radioactive sample due to the decay of the sample, the actual rate is continuously fluctuating because of the random nature of the disintegration process. Thus, a series of similar counting determinations made on the same radioactive sample will, in general, all be different and will be randomly distributed about an average value. Because of the fluctuating rate it is not correct to speak of the true rate of disintegration (which implies no error in the determination of the actual number of particles counted) but rather it is more proper to speak of the true average rate.

Statistical laws may be used to estimate how well an observed counting determination represents the true average value. The actual difference between an observed count and the true average value is called the error of the determination. It is possible to determine the frequency of occurrence of an error of any magnitude by the application of the laws of probability. A complete derivation of the laws goverming variations in radioactive counting based on the laws of probability, is given by Rasettil and also by Fry.2 By approximations which are valid in most counting determinations, it is shown that the probability of occurrence, $P(n)$, of any count, $n$, when the true average count is $r$, can be predicted by Poisson's distribution law:

$$
P(n)=\frac{e^{-r} r^{n}}{n !}
$$

If we make a large number of simflar determinations of equal time duration on the same sample, this formula tells us in what fraction of the total number of determinations we should expect to observe zero, one, two, or more counts.

Numerous statistical and practical considerations make it desirable to use the Gaussian, or Normal, distribution rather than the Poisson distribution in the consideration of counting statistics. Statistical

1. Rasetti, Element of Nuclear Physics, Prentice-Hall, Inc., New York, 1936, pp. 32-35.

2. Fry, Probability and Its Engineering Uses, Van Nostrand, New York, 1928, pp. 235-237. 
properties calculated from any set of data may be computed more easily if the data are considered representative of a Gaussian distribution. If the number of particles, $n$, counted in a given time interval is large, it can be shown, by a transformation of the Poisson distribution law, that the probability of occurrence, $P(n)$, of values of n near the true average, $r$, may be approximated by the Gaussian probability, $G(n)$, distribution:

$$
G(n)=\frac{1}{v 2 \pi r} e^{-\frac{(1-n)^{2}}{2 r}}
$$

If the tmue average count, $r$, of the particles from a certain source is 20 counts in a given interval, the Gaussian probability, $G(n)$, that $n$ will actually be counted during a single similar determination is shown in Table I. Also shown in the table for comparison are the Poisson probabilities, $P(n)$.

\begin{tabular}{|c|c|c|c|c|c|}
\hline $\mathrm{n}$ & $\mathrm{G}_{(\mathrm{n})}$ & $P(n)$ & $n$ & $\mathrm{G}(\mathrm{n})$ & $P(n)$ \\
\hline 0 & 0.0000 & 0.0000 & 20 & 0.0892 & 0.0888 \\
\hline 1 & 0.0000 & 0.0000 & 21 & 0.0870 & 0.0846 \\
\hline 2 & 0.0000 & 0.0000 & 22 & 0.0807 & 0.0769 \\
\hline 3 & 0.0001 & 0.0000 & 23 & 0.0712 & 0.0669 \\
\hline 4 & 0.0002 & 0.0000 & 24 & 0.0598 & 0.0557 \\
\hline 5 & 0.0003 & 0.0001 & 25 & 0.0478 & $0.04 \overline{4} 6$ \\
\hline 6 & 0.0007 & 0.0002 & 26 & 0.0377 & 0.0343 \\
\hline 7 & 0.0013 & 0.0005 & 27 & 0.0262 & 0.0254 \\
\hline 8 & 0.0024 & 0.0013 & 28 & 0.0180 & 0.0181 \\
\hline 9 & 0.0043 & 0.0029 & 29 & 0.0118 & 0.0125 \\
\hline 10 & 0.0073 & 0.0058 & 30 & 0.0073 & 0.0083 \\
\hline 11 & 0.0118 & 0.0106 & 31 & 0.0043 & 0.0054 \\
\hline 12 & 0.0180 & 0.0176 & 32 & 0.0024 & 0.0034 \\
\hline 13 & 0.0262 & 0.0271 & 33 & 0.0013 & 0.0020 \\
\hline 14 & 0.0377 & 0.0387 & 34 & 0.0007 & 0.0012 \\
\hline 15 & 0.0478 & 0.0516 & 35 & 0.0003 & 0.0007 \\
\hline 16 & 0.0598 & 0.0646 & 36 & 0.0002 & 0.0004 \\
\hline 17 & 0.0712 & 0.0760 & 37 & 0.0001 & 0.0002 \\
\hline 18 & 0.0807 & 0.0844 & 38 & 0.0000 & 0.0001 \\
\hline 19 & 0.0870 & 0.0888 & 39 & 0.0000 & 0.0001 \\
\hline
\end{tabular}

To see just how satisfactory this approximation is at 20 counts, refer to Figure 1, in which the probabilities of the Poisson distribution are compared with the probabilities of its Gaussian approximation. The discrepancies between the Poisson probabilities and those given by the Gaussian law are appreciable in every case, but near the center of the range, where the probabilities are high, the percentage error would not 


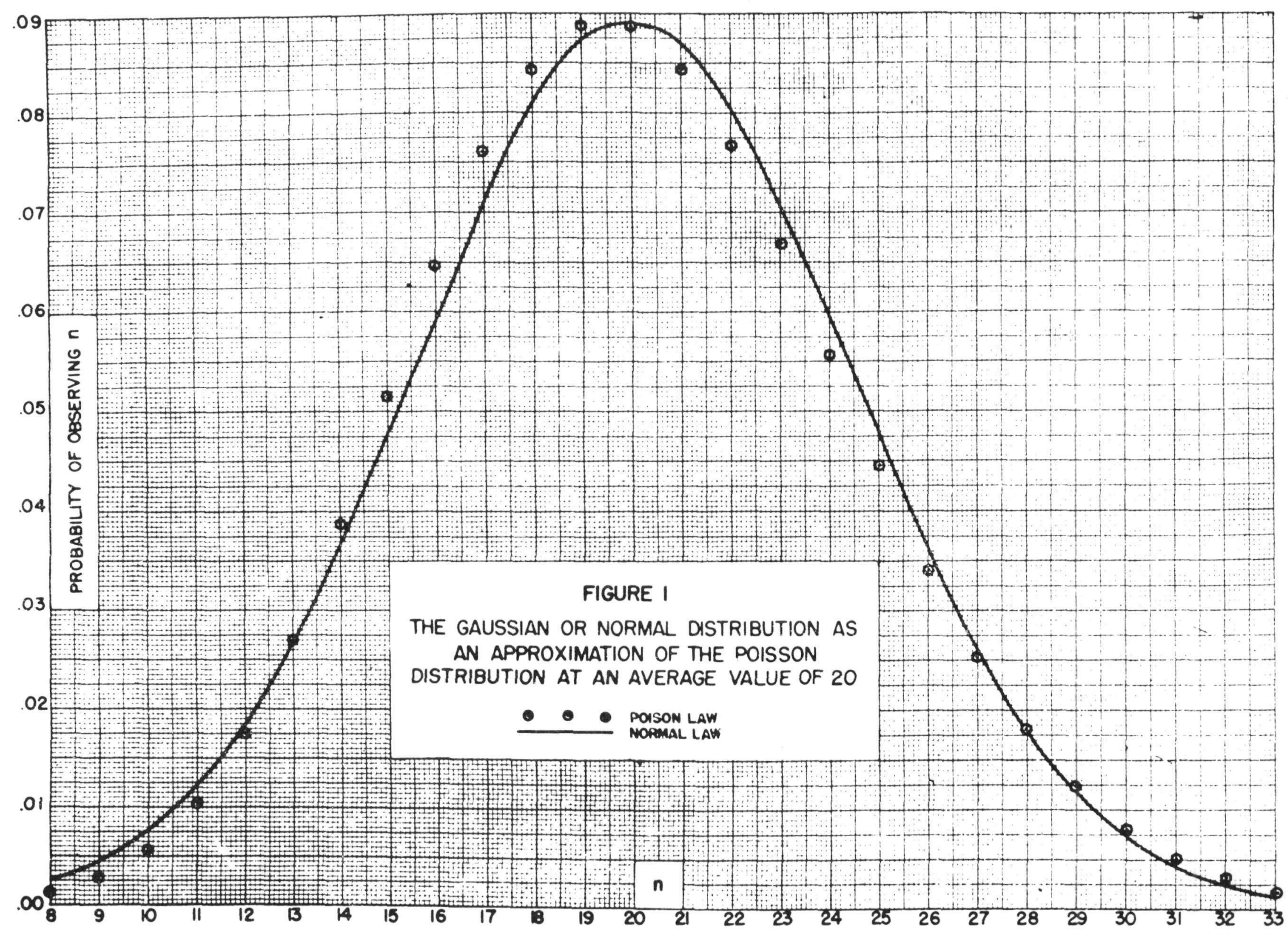


be of serious consequences for counting purposes. Near the tails, however, the percentage error is very large and the Gaussian approximation should not be used in those regions.

Suppose we counted a sample for a given length of time and observed 15 counts. If the true average count on that sample for the same time interval is 20 counts, we find that the Gaussian probability of observing 15 counts, from Table $I$, is 0.0478 . This means we should expect to observe 15 counts about 5 times in 100 similar determinations (of equal time duration) if the true average for a single determination is 20 counts. This particular result is therefore not very likely. However, by glancing over the table, it is seen that no other result is much more likely. Even the probability of observing 20 counts, the true average value, is only 0.0892. Obviously under these circumstances it is unfair to assume that 15 counts is an unreasonable value to observe.

The question that really presents itself is not how likely are wo to observe a particular result, e.g., 15, but how likely are we to observe any result equally, or less probable, than 0.0478 .

Because of the symmetry of the Gaussian distribution curve, this would be equivalent to determining the probability of observing any result differing from the true average by more than five counts. If the error is called $q$, where $q=r-n$, and the Gaussian probability of observing a particular error, $q$, is $G(q)$, then:

$$
G(q)=2 G(n)=\sqrt{\frac{2}{\pi r}} e^{-\frac{q^{2}}{2 r}}
$$

and the summation probability $G_{s}(b)$ for the error to be larger than a particular value of $q$, say $b$, is:

$$
G_{S}(b)=\sqrt{\frac{2}{\pi r}} \int_{b}^{\infty} e^{-\frac{q^{2}}{2 r}} d q
$$

This equation, by a change in variable, can be put into a form for which tables are available for evaluating the integral.

Let $q=K \sqrt{r}$ where $r$ is held constant.

Then

$$
\mathrm{dq}=\sqrt{\mathrm{r}} \mathrm{dK}
$$

and

$$
\begin{aligned}
b & =K_{1} \sqrt{r} \\
G_{S}(b) & =G_{S}\left(K_{1} \sqrt{r}\right)=\sqrt{\frac{2}{\pi}} \int_{b_{1} \sqrt{r}}^{\infty} e^{-\frac{K^{2}}{2}} d K
\end{aligned}
$$

Thus 
The definite integral above has been evaluated with the aid of tables 3 , and the probability $G_{S}(K \sqrt{r})=G_{S}(q)$ of observing an error larger than $q=K \sqrt{r}$ for various values of $K$ is shown in Table II.

other values of $K$ and $G_{S}(K \sqrt{r})$ may be found on the graph of Figure 2, which plots $K$ vs $G_{S}(K \sqrt{r})$ or in the literature. 3

Table II--Probability of Error with Gaussian Distribution

\begin{tabular}{cc}
\hline \hline$G_{S}(q)=G_{S}(K \sqrt{r})$ is the probability of observing \\
an error larger than $q=K \sqrt{r}$
\end{tabular}

In the example under consideration, the probability of observing a result in error by more than 5 counts when the true average is 20, is calculated by solving for $K$ in the expression $K=q / r^{1 / 2}$ and finding the value of the probability from Figure 2, thus obtaining 0.3711. That is, there are 3711 chances out of 10,000 of observing a result equally or

3. W.P.A., Tables of Probability Functions, Volume II, Washington, D. C., 1942 .

Fry, op. cit., pp. $453-455$.

Peters and Van Voorhis, Statistical Procedures and Their Mathematical Bases, McGraw-Hill, liew York, 1940, pp. 485-487.

Crumpler and Yoe, Chemical Computations and Errors, Wiley, New York, 1940, p. 232.

Blair, Elementary Statistics, Holt, New York, 1944, p. 650.

Croxt on and Cowden, Applied General Statistics, Prentice-Hall, New York, 1944, p. 873.

Fisher, Statistical Methods for Research Workers, Oliver and Boya, London, 1944, p. 77 .

Lange, Handbook of Chemistry, Handbook Publishers Inc., Sandusky, Ohio, 1941, pp. 257-260.

Hedgman, Handbook of Chemistry and Physics, Chemical Rubber Publishing Co., Cleveland, 1944, pp. 200-204. 


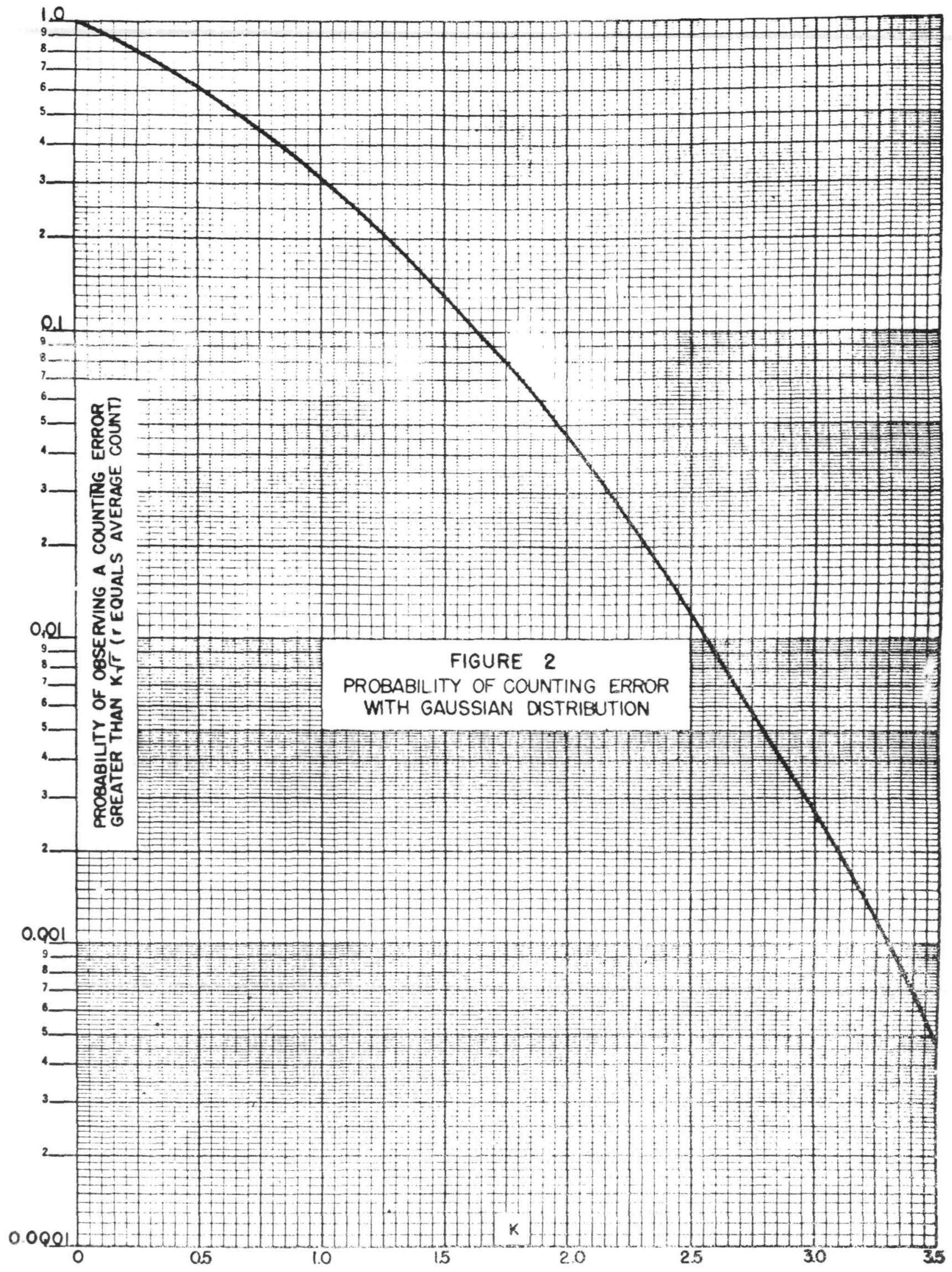


less probable than 15 counts during a single determination of a count whose true average for that determination is 20 counts. Because the probability of observing a result at least as unlikely as 15 is 0.3711 , which is quite large, we can assume that 15 is a result which might reasonably occur during a given interval due to chance variations in the disintegration rate of a sample whose true average count for that interval is 20 counts. It could also be shown that there is a very definite chance, 0.0253, of observing a result which is in error by as much as 10 counts in a single counting determination of a radioactive source whose true average is 20 counts for a similar determination.

In practice we can arbitrarily select a limit of error, sometimes expressed as a percentage of the average value, and calculate the probability that the observed value is in error by at least the amount of the selected error. If this probability is small, the observed count is considered acceptable as a reliable estimate of the true average value. If the probability is large it is necessary to accumulate more data until the probability becomes low enough to be satisfactory. The problem thus becomes that of determining just how small the probability should be before we can regard chance variations as having been virtually eliminated as a factor in the determination.

Standard statistical practices usually set this probability limit at 0.05 and for more rigid interpretations at 0.01 . For general radiochemical applications, this probability is commonly set at 0.10 . There are nine chances out of ten that the actual error of a determination will be less than the error having a probability limit of 0.10 . For this reason an error having a probability limit of 0.10 is quite often called the nine tenths error. This error may also be expressed as a fraction of the average count and is then called the fractional nine tenths error or as a percentage of the average and called the percent nine tenths error. Similarly, errors having probability limits of 0.05 and 0.01 are called the ninety-five hundredths error and the ninety-nine hundredths error, respectively. 4 The probable error is standard nomenclature designating the error with a probability limit of 0.50 . The standard deviation is the error for which $K$ equals 1.0000 with a corresponding probability of 0.3173 and thus in counting is numerically equal to the square root of the true average count. Probability tables are usually computed in terms of multiples of the standard deviation. 3 Because of the limitations imposed by assuming a Gaussian approximation to the Poisson distribution, the values of $\mathrm{K}$ in Table II and Figure 2 should not be used when the true average count of a determination is less than ten counts. The most satisfactory level of significance of all is to ascertain the probability that a given deviation might occur because of chance, and then decide whether or not chance has been reduced to a low enough level for the particular problem at hand.

EXAMPIE

The nine tenths error of a single determination on a radioactive source whose true average count for this determination is 20 counts, would be $1.645 \times \sqrt{20}=7.356$ counts. The fractional nine tenths error

4. Other error limits of various probabilities are simflarly designated. 
would then be $7.356 / 20=0.3678$ and the percent nine tenths error, therefore, $36.78 \%$.

Table III summarizes the discussion of the most important errors used in statistical analysis.

In practice, if we wish to compute any of these errors, we do not know $r$, the true average count, but rather $n$, an observed value, which may deviate, as we have seen, rather considerably from $r$. Thus it is necessary, in order to estimate the error of a counting determination, to use the observed result as an approximation to the true average value. It is obvious then, that an error calculated from the observed determination would not be an absolute and invariable quantity which may be reproduced whenever we wish by performing the experiment anew. Another experiment would very likely give us a different result. All possible results are not equally likely, however. The values of the error which we get are governed by probability in just the same way as any other quantity which is subject to random fluctuations. The magnitude of these variations does not often warrant the use of more than two significant figures in the value of an error. It should be noted that these variations in the error are of a second order (square root variation) compared to the variations in the count. Thus, in practice, the error of a counting determination would be $K$ times the square root of the number of particles actually counted, where $K$ is the proportionality constant found in Table II or Figure 2.

\section{EXXMPIE}

The nine tenths error of a single determination in which 15 counts were recorded would be estimated a $1.645 \sqrt{15}=6.4$ counts. The fractional nine-tenths error would then be $6.4 / 15=0.43$ and the percent nine-tenths error would be $43 \%$. If the true average count of this sample were twenty counts, this would differ from the more nearly correct value of the nine-tenths error calculated previously by about $15 \%$, which is not significant for all practical purposes.

\section{THE ERRORS IN COUNTING RATE DETERMINATIONS}

It is customary to describe the activity of a radioactive sample in rate terminology and thus if $n$ particles from a certain sample were observed in $t$ minutes, the counting rate $\mathbb{N}$ of the sample would be

$$
\mathrm{N}=\mathrm{n} / \mathrm{t}
$$

The estimate of the error $\mathrm{q}$ in the determination would be

$$
q=K \sqrt{n}=K \sqrt{\mathrm{Nt}}
$$

The estimate of the error $Q$ in the determination of the rate is thus

$$
Q=q / t=\frac{K \sqrt{N t}}{t}=K \sqrt{N / t}
$$


Table III--Summary of the Errors Most Used in Statistical Analysis

(In the table below, $\mathrm{n}$ is the total number of observed counts)

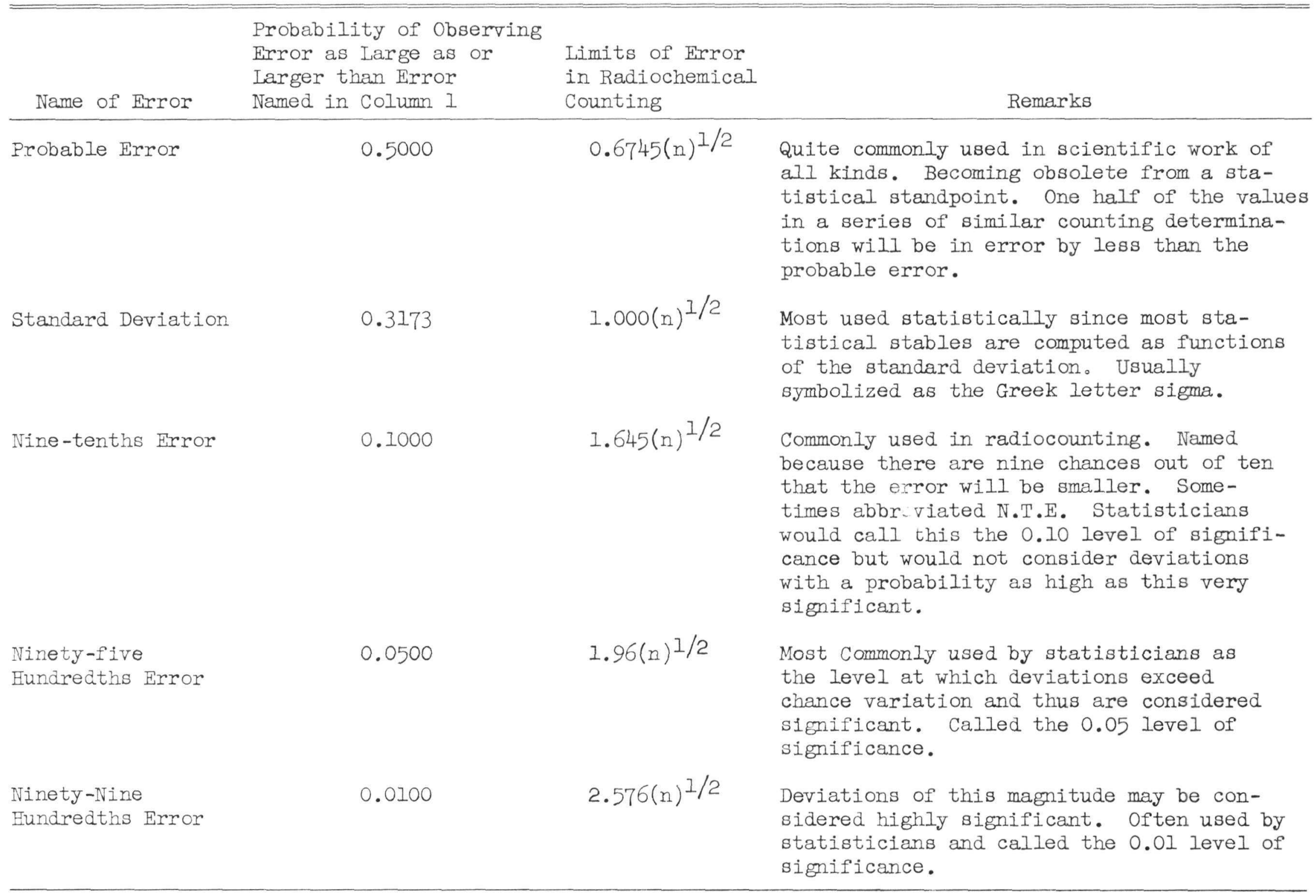


The estimate of the fractional error $F$ in the determination of the rate would then be

$$
F=Q / N=\frac{K \sqrt{N / t} K}{N \sqrt{N t}}
$$

It has been stated that the limit of random error in radiocounting has been set at the 0.10 probability limits. This choice is highly arbitrary and hence this limit cannot be accepted as an inflexible dictum. Individual cases will require separate consideration. The following chart, Figure 3, has been prepared to facilitate the calculation of the nine-tenths error and other commonly used limits of error. The chart was prepared by plotting the total number of counts observed, (Nt), against the fractional error, $F$, for various values of $K$ as a parameter. To determine the value of the error for probability limits not shown on the graph, the value of the percent standard deviation is multiplied by the appropriate value of $\mathrm{K}$ found in Table II or Figure 2.

\section{EXAMPLE}

What is the 0.999 error when a 1250 counts per minute sample is counted for 4 minutes?

The total number of counts is, Nt $=1250 \times 4=5000$ counts.

From Figure 3 the percent standard deviation is 1.4\%. The standard deviation is thus: $1.4 / 100 \times 1250=17.5$ counts per minute.

The value of $K$ is 3.29 for the 0.999 error (as determined in Table II) and thus the 0.999 error is, $17.5 \times 3.29=58$ counts per minute.

All the advantages of graphical representation are retained when counting errors are calculated nomographically.5 In addition the nomographic, or alignment, chart affords four definite advantages over the rectangular coordinate graph:

1. Higher degree of precision.

2. Less chance for mistakes.

3. When three variables are presented on the same chart, all interpolations are made along graduated scales rather than between curves.

4. Unskilled personnel can perform difficult interpolations and computations more readily and with less chance of error.

Figure 4 is a nomograph which is useful for calculating the 0.9 error and the 0.95 error of counting rate determinations from 1 count per minute to 100,000 counts per minute. The chart is used as follows:

Draw a straight line from a point on the left scale corresponding to the counting rate of the sample under consideration, through the point on the right scale corresponding to the number of minutes the sample was counted. The point where this line crosses the center scale corresponds to the 0.9 error and the 0.95 error of the determination.

5. A detailed discussion of the construction and use of nomographs is given by Davis, Empirical Equations and Nomography, McGraw-Hill, 1943. 


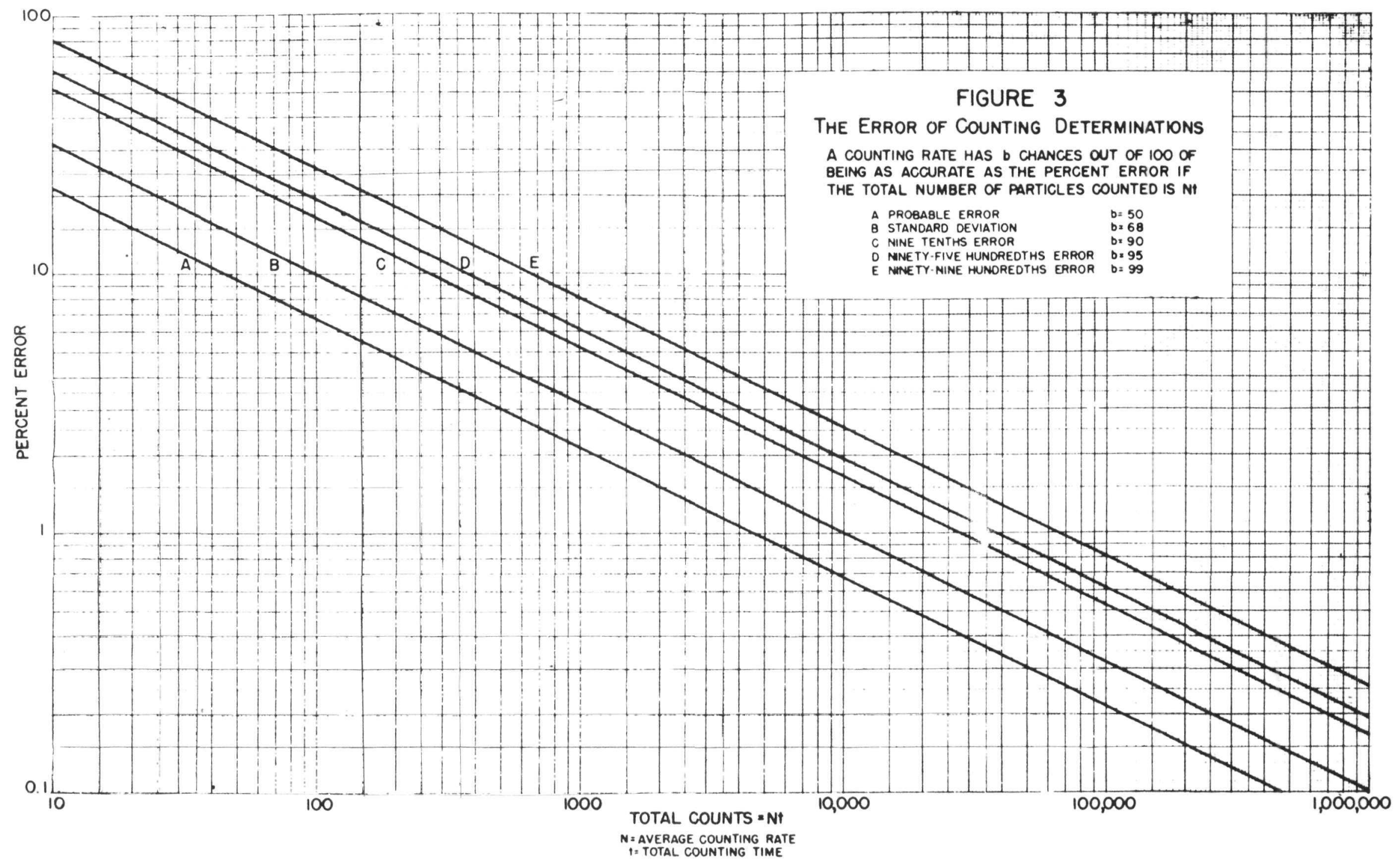


AVERAGE

CONTING RATE

F 100,000

奉

10,000

I

$+2$

20,000

$=10,000$

8,000

t

t

$-1,000$

青

$\neq$

f

$-200$

100

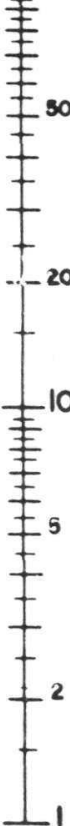

0.9 ERROR O.95 ERROR

E 500

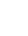

FIGURE 4

THE 0.9 ERROR AND 0.95 ERROR of

COUNTINg Rate Determinations

INSTRUCTIONS FOR USE

Draw a straight line from a point on the left scale corresponding to the counting rate of the sample through the point on the right scale corresponding to the length of time the sample was counted. The point where this line crosses the center scale corresponds to the 0.9 error and the 0.96 error of the determination.

Example:

The 0.9 error of a sample which averaged 1250 counts per minute during a four minute determination is 29 counts per minute.

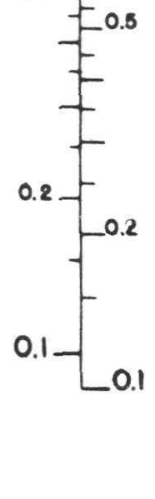




\section{EXAMPIE}

What is the 0.9 error of a sample which averages 1250 counts per minute during a 4 minute determination?

A straight line is drawn on Figure 4 between 1250 on the left scale and 4 on the right hand scale. The 0.9 error is read at the intersection of this line with the center scale and is seen to be 29 counts per minute.

Figure 5 is a nomograph which is useful for calculating the percent error for probability limits from 0.50 to 0.00001 and for any counting determination from 10 to 1,000,000 counts. The chart is used as follows:

Draw a straight line from a point on the left scale that corresponds to the total number of counts observed (i.e., the average rate multiplied by the total time of counting) through the point on the right scale that corresponds to probability limits for which the error is to be determined. The point where this line crosses the center scale will correspond to the percent error having the desired probability limits.

\section{EXAMPIE}

A sample was counted for 4 minutes and averaged 1250 counts per minute. What is the 0.999 error? Nt $=1250 \times 4=5000$ counts.

A straight line is drawn on Figure 5 between 5000 on the left scale and 0.001 on the right hand scale. The percent 0.999 error is seen to be $4.6 \%$ and thus the 0.999 error is: $4.6 / 100 \times 1250=58$ counts per minute.

\section{THE ERROR INTRODUCED BY THE BACKGROUND}

In practice the actual counting rate of a radioactive sample cannot be determined directly but must be calculated by subtracting the independently determined background rate from the recorded rate of the sample counted with the background present. The background rate is determined by taking a count with no sample present although a dummy sample and holder may be used in the determination for the maximum accuracy. Fluctuations in the counting rate of background arise from the same causes and are governed by the same laws as fluctuations in the disintegration rate of radioactive samples. Thus when 10 or more counts are recorded for a background determination, the principles developed in the preceding section will apply and the error of the background counting rate determination can be calculated from the formula

$$
\mathrm{Q}_{\mathrm{b}}=\mathrm{K}\left(\mathrm{N}_{\mathrm{b}} / \mathrm{t}_{\mathrm{b}}\right)^{1 / 2}
$$

Where the value of $K$ is taken from Table II or Figure 2. Figures 3 or 4 may also be used to calculate the errors of a background determination.

Because of the statistical fluctuations in the counting rate of the background it is not possible to determine the counting rate of a radioactive sample as accurately as if no background were present. It is thus important to ascertain the effect which the uncertainties in the counting rates of both the background rate and the counting rate of the sample including the background would have upon the values of the actual rate of the sample computed from these two quantities. The problem then is to determine the error of the difference of two quantities for which the errors can be evaluated. 


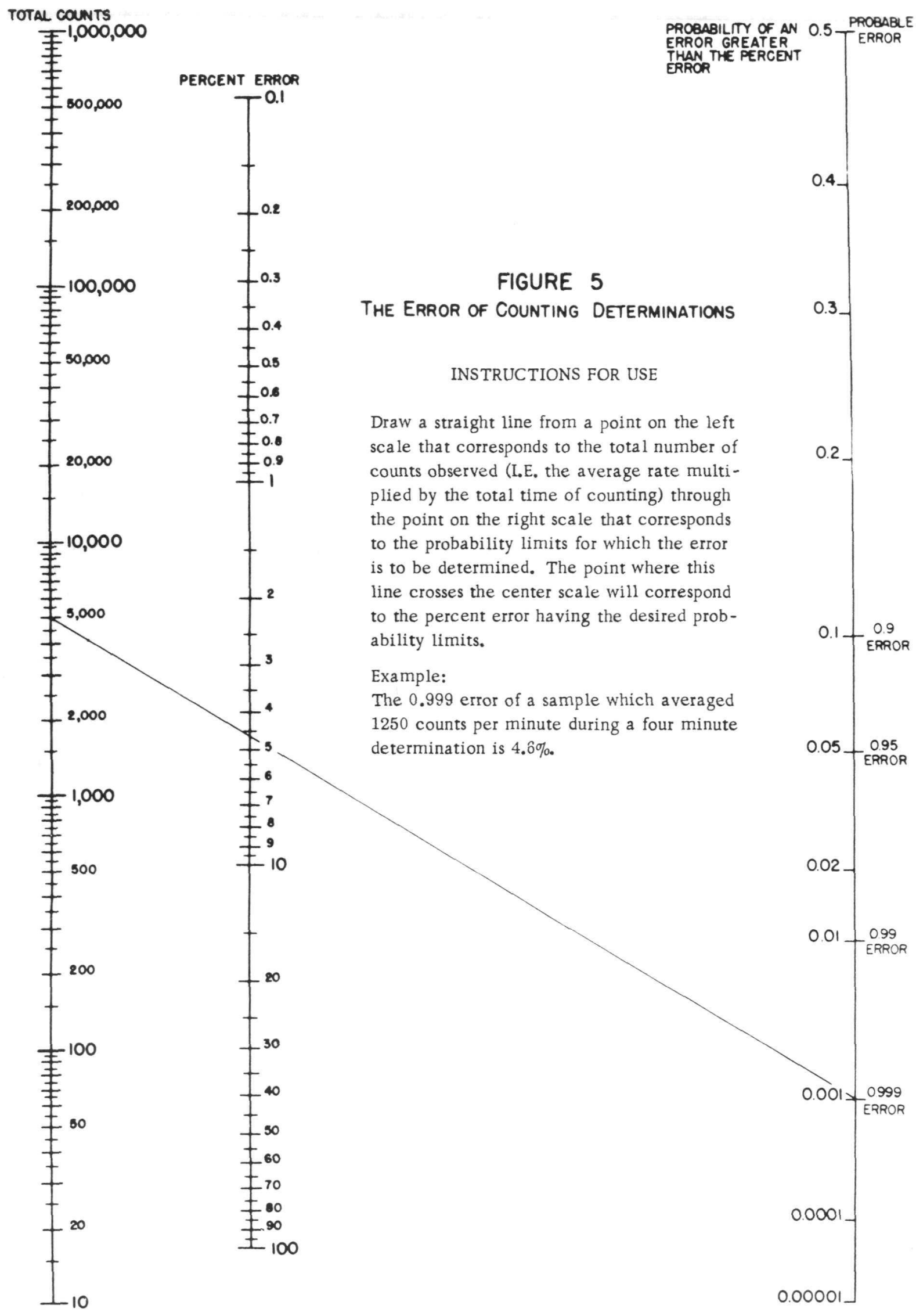


Because the fluctuations in a function of independently observed quantities occur in accordance with the same law of error as those of the quantities themselves, the fluctuations of the difference of the counting rate of a sample with background and the background rate will occur in accordance with the Poisson Law and also its Gaussian approximation. As a result of the Gaussian theory of the distribution of errors, the error, $\mathrm{y}$, of the difference of two counting determinations, $\mathrm{N}_{\mathrm{S}}-\mathrm{N}_{\mathrm{b}}$, can be shown 6 to be:

$$
y=\left(Q_{S}^{2}+Q_{b}^{2}\right)^{1 / 2}
$$

where $Q_{s}$ is the error (probable, nine-tenths or any other) in the determination of $N_{S}$, the counting rate of the sample including the background, and $Q_{b}$ is the error in the determination of $\mathrm{N}_{b}$, the counting rate of the background.

But we have shown that

$$
\mathrm{QS}=\mathrm{K}\left(\mathrm{N}_{\mathrm{S}} / \mathrm{t}_{\mathrm{S}}\right)^{1 / 2}
$$

and

$$
\mathrm{Qb}=\mathrm{K}\left(\mathrm{N}_{\mathrm{b}} / \mathrm{t}_{\mathrm{b}}\right)^{1 / 2}
$$

and therefore the error, $\mathrm{y}$, of a counting rate determination $\mathrm{N}_{S}-\mathrm{N}_{\mathrm{b}}$ is

$$
y=\sqrt{\left[K\left(N_{S} / t_{S}\right)^{1 / 2}\right]^{2}+\left[K\left(N_{b} / t_{b}\right)^{1 / 2}\right]^{2}}=K\left(N_{S} / t_{S}+N_{b} / t_{b}\right)^{1 / 2}
$$

where $K$ is a constant taken from Table II or Figure 2.

\section{EXXMPIE}

A sample was counted for 7 minutes and averaged 28.0 counts per minute. The background was counted for 4 minutes and averaged 20.0 counts per minute. What is the 0.95 error?

$$
N_{S} / t_{S}=28 / 7=4.0 \quad N_{b} / t_{b}=20 / 4=5.0 \quad K=1.96
$$

$y=1.96 \sqrt{4.0+5.0}=1.96 \sqrt{9}=1.96 \times 3=5.9$ counts per minute. Thus the result would be written $8.0 \pm 5.9$.

For rapidity and convenience of calculation, the error in the counting rate determination, $\mathbb{N}_{S}-N_{b}$, may be calculated nomographically. Figures 6 and 7 and nomographic charts which can be used to calculate the 0.9 error and the 0.95 error of counting rate determinations in which the background is an appreciable fraction of the total counting rate. Figure 6 is used for errors less than one count per minute. Figure 7 is used for

6. Croxton and Cowden, op. cit., pp. 841-842. Crumpler and Yoe, op. cit., pp. 174-177. Peters and Van Voorhis, op. cit., pp. 160-163, pp. 176-177. Worthing and Geffner, Treatment of Experimental Data, Wiley, New York, 1943, pp. 206-207. 


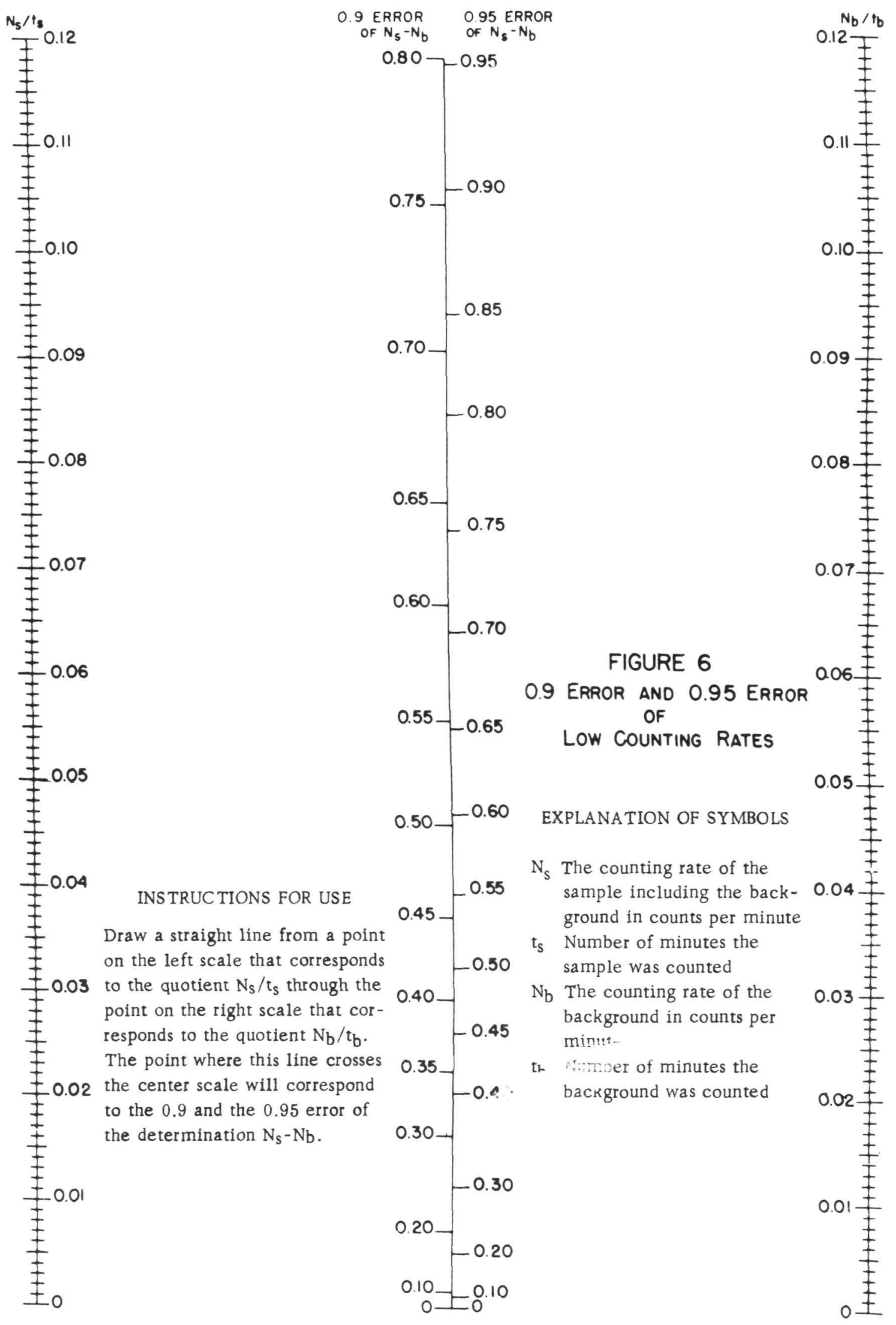



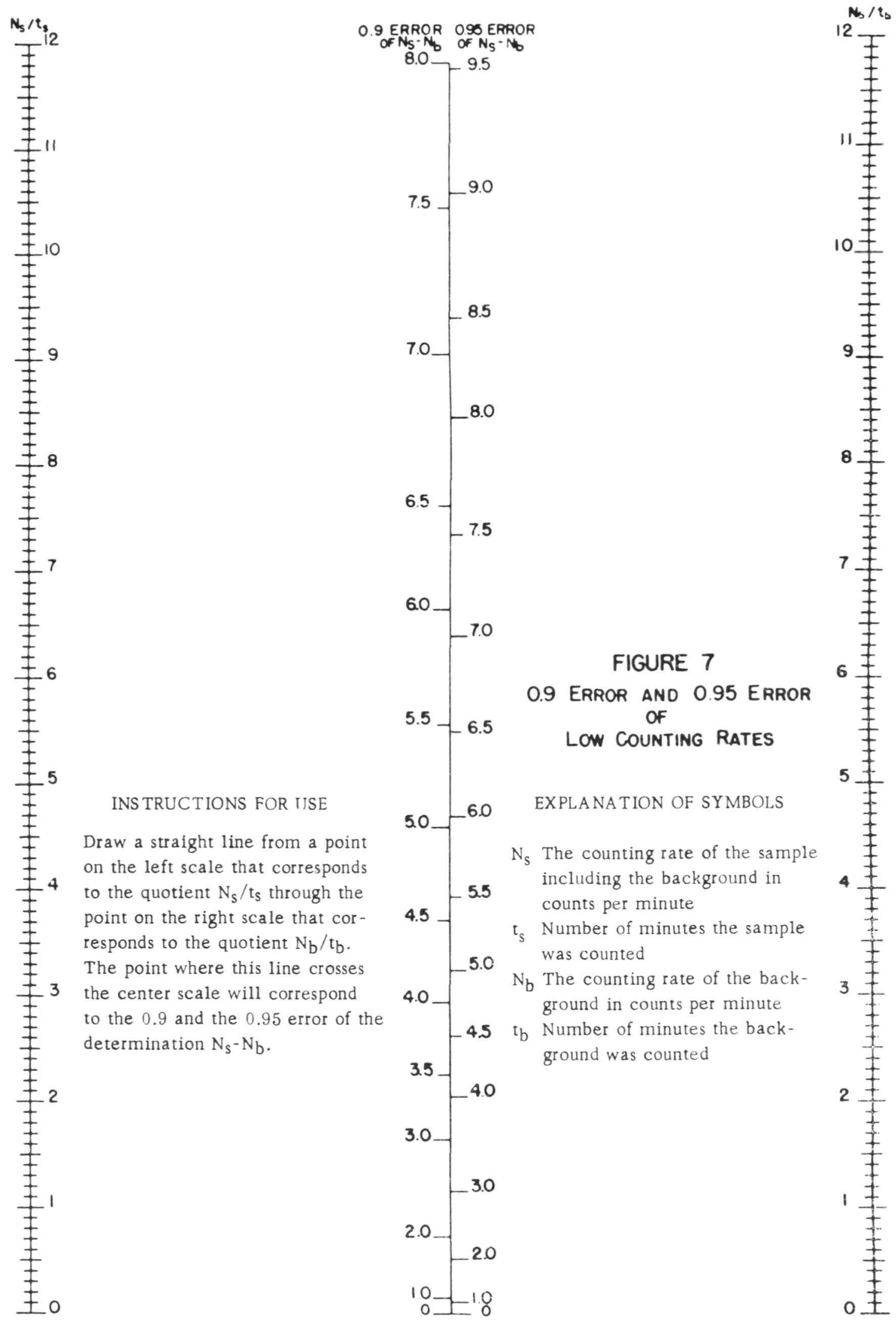
errors less than ten counts per minute. The charts may also be used to determine whether or not a counting rate determination is significantly different from zero. If the 0.95 error is less than the counting rate of the sample after the background has been subtracted, the determination is usually considered significantly different from zero.

Figure 8 is a nomograph chart designed to calculate the 0.9 error and the 0.95 error of higher counting rates than those found on Figures 6 and 7. If it is not possible to calculate the error of certain determinations on these nomographs, the additional error introduced by the background is probably insignificant compared to the error introduced by the measurement of the sample and thus Figures 3, 4, or 5 can be used to calculate this error. Any of these errors may of course be calculated by use of the formula for the error of a counting rate determination, $N_{S}-N_{b}$.

It should be noted that before using the nomographic charts, it is necessary to criculate the quotients:

1. $\mathbb{N}_{S} / t_{S}$, that is the counting, rate of the sample, including the background, divided by the number of minutes that sample was counted.

2. $N_{b} / t_{b}$, the counting rate of the background divided by the number of minutes the background was counted.

Charts 6, 7, and 8 are used in the following manner:

Draw a straight line from a point on the left scale that corresponds to the quotient $\mathrm{N}_{\mathrm{S}} / \mathrm{t}_{\mathrm{S}}$ through the point on the right scale that corresponds to the quotient $\mathrm{N}_{\mathrm{b}} / t_{\mathrm{b}}$. The point where this line crosses the center scale will correspond to the 0.9 and the 0.95 error of the determination $\mathrm{N}_{\mathrm{S}}-\mathrm{N}_{\mathrm{b}}$.

\section{EXAMPIE}

A sample was counted for 10 minutes and averaged 2000 counts per minute. The background was counted for one minute and 16 counts were recorded in that interval. Since 2000 divided by 10 equals 200 , and 20 divided by 1 equals 20, it is obviously necessary to use Figure 8 for this calculation. A straight line is drawn between the two points on the left and right scales respectively. The 0.9 error is thus seen to be 24 counts per minute and the 0.95 error of the determination 29 counts per minute.

\section{EXAMPIE}

A sample was counted for 64 minutes and averaged 3.20 counts per minute. The background was counted for 58 minutes and averaged 2.60 counts per minute. Since 3.20 divided by 64 equals 0.05 and 2.60 divided by 58 equals 0.045 , it is necessary to use Figure 6 for this calculation. A straight line is drawn between 0.05 on the left scale and 0.045 on the right scale. The 0.9 error is thus seen to be 0.51 counts per minute and the 0.095 error of the determination 0.604 counts per minute. The counting rate of the determination is 3.20 minus 2.60 equals 0.60 counts per minute. Because this counting rate is less than the 0.95 error, it is considered not significantly different from zero on the basis of this determination. 


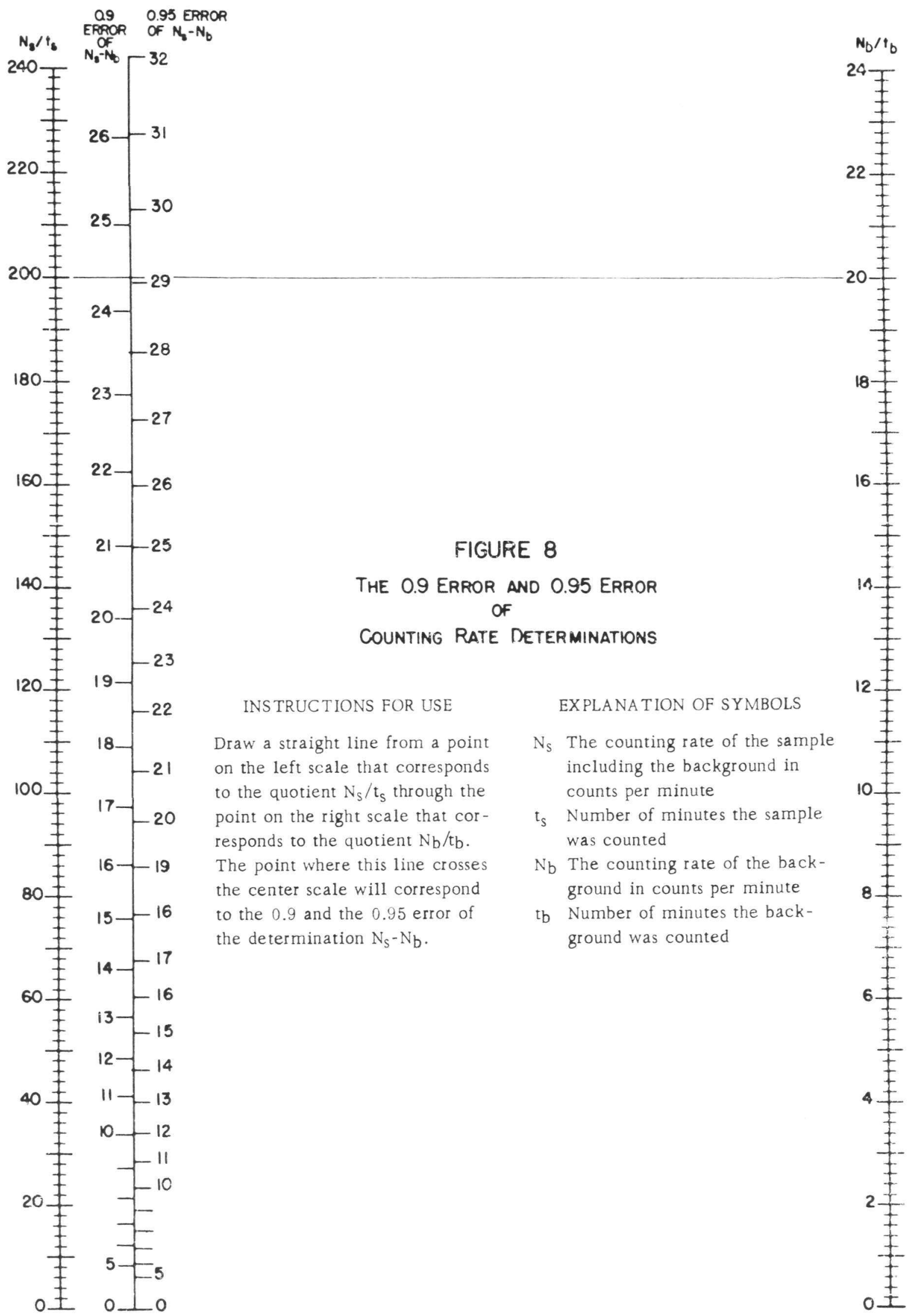


Figure 9 is a nomograph designed to facilitate calculation of the probability limits of any error up to fifty counts per minute in a counting determination $N_{S}-N_{b}$. It can also be used to determine the magnitude of the probable error, the standard deviation, the nine-tenths error and other errors useful in a statistical evaluation of the counting determination $N_{S}-N_{b}$. The chart is used in the following manner:

Draw a straight line from a point on scale A which corresponds to the quotient $\mathbb{N}_{\mathrm{S}} / \mathrm{t}_{\mathrm{S}}$ through the point on scale $\mathrm{B}$ which corresponds to the quotient $\mathrm{N}_{\mathrm{b}} / \mathrm{t}_{\mathrm{b}}$. The intersection of this line with scale $\mathrm{C}$ is noted. A second straight line is drawn between this noted reference point on scale $C$ and the type of error desired on the diagonal scale D. The particular error desired will be found at the intersection of this second line with Scale E.

\section{EXAMPIE}

What is the 0.99 error of the determination of the counting rate of a sample which averaged 2000 counts per minute in a 10 minute determination with a 19 count per minute background present? The background was counted for one minute. As indicated by the example on Figure 9, a straight line is drawn between the points 2000/10 equals 200 on scale A and $19 / 1$ equals 19 on scale B. A second straight line is drawn through the intersection of the first line with scale $C$ and the point on scale D corresponding to the 0.99 error. The 0.99 error is read on scale $\mathrm{E}$ and is seen to be 38 counts per minute. This corresponds to a $38 / 1981 \times 100$ equals $1.9 \% 0.99$ error.

THE ERROR OF THE PRODUCT OR QUOTIENT OF A SERIES OF COUNTING RATE DETERMINATIONS

In addition to the particular instance just described, there are a greet number of other cases in which the quantity sought cannot be measured directly but must be calculated from the results of two or more other experiments on directly measured quantities. It is, of course, just as desirable to know the accuracy of such indirectly measured quantities. Thus, for example, when determining the disintegration rate of a radioactive sample by multiplying the observed counting rate by the geometrical factor, it is important to know just how inaccuracies in both the geometry factor and the observed counting rate will affect the calculated value of the disintegration rate.

In this section we will consider the determination of the error of a result obtained by multiplication and division of directly measured quantities. Subsequently we will consider the cases of the error in an addition, the error in the determination of the arithmetic mean and finally, the error in the general case involving any function of directly measured quantities.

It can be shown7 that the fractional (or percentage) error of a result obtained by multiplication and division is equal to the square root

7. Worthing and Geffner, op. cit., pp. 207-208. 


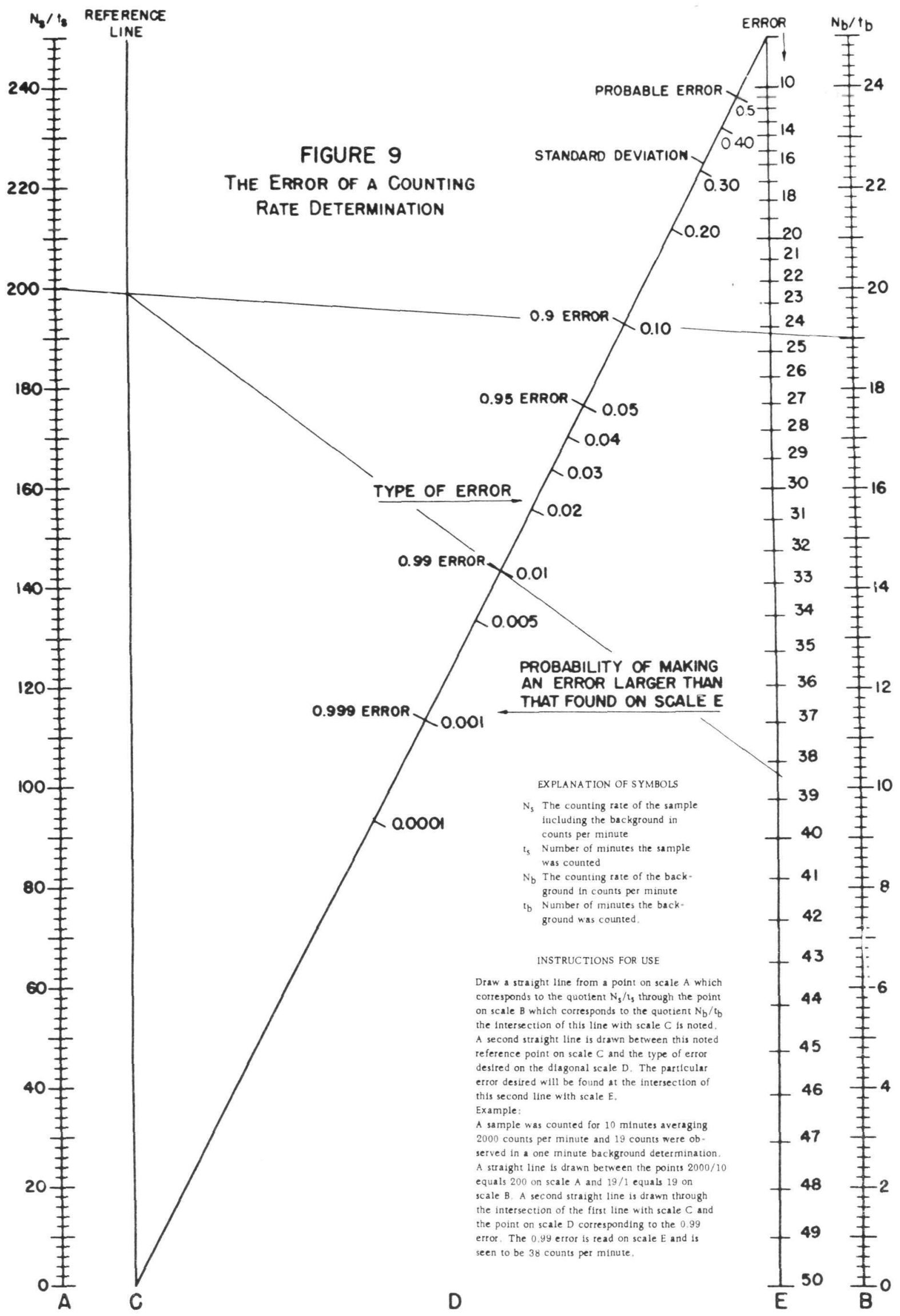


of the sum of the squares of each of the fractional (or percentage) errors of each of the independent (directly observed) variables which determine the function.

Consider the case in which $U$ is determined by calculation from observations on four directly measured quantities, $W, X, Y$, and $\mathrm{Z}$ by use of the equation

$$
\mathrm{U}=\frac{\mathrm{WX}}{\mathrm{YZ}}
$$

If the error in $U$ is designated $u$ and the errors in each of the directly measured quantities $W, X, Y$, and $Z$ are respectively designated $w, x, y$, and $z$, the fractional error in $U$ would be:

$$
\frac{\mathrm{u}}{\mathrm{U}}=\sqrt{\left(\frac{\mathrm{w}}{\mathrm{W}}\right)^{2}+\left(\frac{\mathrm{x}}{\mathrm{X}}\right)^{2}+\left(\frac{\mathrm{y}}{\mathrm{Y}}\right)^{2}+\left(\frac{\mathrm{z}}{\mathrm{Z}}\right)^{2}}
$$

\section{EXAMPIE}

In determining the disintegration rate of a sample counted on the low geometry alpha counter, one uses the formula

$$
\mathrm{D}=\mathrm{GN}
$$

where $G$ is the geometry factor used for converting the observed counting rate $\mathrm{N}$, into the disintegration rate, D. If a sample averaged 225 counts per minute when counted for 4 minutes at $0.1 \%$ geometry and the nine-tenths error in the geometry is estimated at $5 \%$, the fractional nine tenths error would be calculated by using the above formula.

The fractional nine tenths error of the counting rate is determined from Figure 3 (or Figure 5) and found to be 5.5\%. The fractional nine tenths error in the disintegration rate would then be

$$
\left(5.5^{2}+5^{2}\right)^{1 / 2}=55.25^{1 / 2}=7.4 \%
$$

THE ERROR IN THE SUM OF A SERIES OF COUNTING DETERMINATIONS

Occasionally the results of a series of counting determinations must be added or subtracted in order to comput the final result and thus it is desirable to know the accuracy of the sum

$$
B_{m}=N_{1} \pm N_{2} \pm N_{3} \pm . . . \pm N_{m}
$$

If $Q$ is the error in the determination of each of the N's counted for time $t$, it can be $\operatorname{shown}^{8}$ that the error in $B_{m}$ will be:

8. Worthing and Geffner, op. cit., pp. 206-207. Crumpler and Yoe, op. cit., p. 177 . 


$$
y_{m}=\left(Q_{1}^{2}+Q_{2}^{2}+\ldots .+Q_{m}^{2}\right)^{1 / 2}
$$

Since

$$
\mathrm{Q}=\mathrm{K}(\mathrm{N} / \mathrm{t})^{1 / 2}
$$

and therefore

$$
Q^{2}=K^{2}(N / t)
$$

the error in $B_{m}$ would be:

$$
\mathrm{y}_{\mathrm{m}}=\mathrm{K}\left(\mathrm{N}_{1} / \mathrm{t}_{1}+\mathrm{N}_{2} / \mathrm{t}_{2}+\ldots+\mathrm{N}_{\mathrm{m}} / \mathrm{t}_{\mathrm{m}}\right)^{1 / 2}
$$

The error of the sum or difference of a series of counting determinations can thus be calculated by determining the error in each of the determinations from Figures 3 or 4, and taking the square root of the sum of the squares of the errors.

\begin{tabular}{|c|c|c|c|}
\hline $\begin{array}{c}\text { Sample } \\
\text { No. }\end{array}$ & $\begin{array}{c}\text { Description } \\
\text { of Sample }\end{array}$ & $\begin{array}{c}\text { Counting Rate } \\
\text { Including back- } \\
\text { ground }\end{array}$ & $\begin{array}{l}\text { Counting } \\
\text { Rate of } \\
\text { Sample }\end{array}$ \\
\hline A & $\begin{array}{l}\text { Starting } \\
\text { Material }\end{array}$ & $200 \mathrm{c} / \mathrm{m}$ & $180 \mathrm{c} / \mathrm{m}$ \\
\hline B & $\begin{array}{l}\text { Product after } \\
\text { Separation }\end{array}$ & $160 \mathrm{c} / \mathrm{m}$ & $140 \mathrm{c} / \mathrm{m}$ \\
\hline $\mathrm{C}$ & Waste & $40 \mathrm{c} / \mathrm{m}$ & $20 \mathrm{c} / \mathrm{m}$ \\
\hline
\end{tabular}

\section{EXAMPIE}

The data for a particular separation experinent is listed in the following toble:

The background (D) counted 20 counts per minute in a four-minute determination. It should be noted that there are 20 counts per minute or about 10\% of the activity unaccounted for. The question arises, "Is this loss statistically significant?" The standard deviation of the deviation of the determination, (A-D) - (B-D) $-(C-D)$, is

$$
\sqrt{(200 / 4+20 / 4+160 / 4+20 / 4+40 / 4+20 / 4)}=10.7 \mathrm{c} / \mathrm{m} \text {. }
$$

We can now calculate the probability of observing a counting error of 20 $\mathrm{c} / \mathrm{m}$ when the standard error of the determination is $10.7 \mathrm{c} / \mathrm{m}$. The ratio of 20/10.7 is 1.87. From the curve of Figure 2 we find a probabillty of 0.06 of observing a counting error greater than $K \times \sqrt{r}$ equals 20 , when $K$ is 1.87. See pp. 33-34 for a discussion of the significance of this probability. 
THE ERROR IN THE MEAN OF A SERIES OF COUNTING DETERMTNATIONS

The best value of a counting rate is often calculated as the arithmetic mean of a series of similar counting determinations and thus it is desirable to know the reliability of the average of these determinations. The arithmetic mean is computed from a series of measured values by use of the formula:

$$
A=\frac{N_{1}+N_{2}+N_{3}+\cdot \cdot \cdot+N_{m}}{m}
$$

The mean, A, is therefore a function of each of a series of independently determined values of $N$. The error in A can be shown to be:

$$
y_{m}=\sqrt{\frac{Q_{1}^{2}}{m^{2}}+\frac{Q_{2}^{2}}{m^{2}}+. \cdot \cdot+\frac{Q_{m}^{2}}{m^{2}}}
$$

where $Q$ is the error in each of the $N^{\prime} s$ previously shown to be:

$$
\mathrm{Q}=\mathrm{K} \sqrt{\mathrm{N} / \mathrm{t}}
$$

and therefore, since

$$
\mathrm{Q}^{2}=\mathrm{K}^{2}(\mathrm{~N} / \mathrm{t})
$$

the error of the mean of a series of counting determinations is

$$
y_{m}=K \sqrt{\frac{N_{1} / t_{1}+N_{2} / t_{2}+\cdot \cdot+N_{m} / t_{m}}{m^{2}}}
$$

When $\mathrm{t}_{1}=\mathrm{t}_{2}=\mathrm{t}_{3}=. .=\mathrm{t}$

$$
y_{m}=K \sqrt{\frac{N_{1}+N_{2}+\cdot \cdot \cdot+N_{m}}{t^{2}}}
$$

But

$$
\mathrm{N}_{1}+\mathrm{N}_{2}+\cdot \cdot+\mathrm{N}_{\mathrm{m}}=\mathrm{mA}
$$

Therefore, the error of the mean of a series of similar counting determinations is:

$$
y_{m}=K \sqrt{\frac{m A}{t^{2}}}=K \sqrt{\frac{A}{t m}}
$$

and the fractional error

$$
\mathrm{F}_{\mathrm{m}}=\frac{\mathrm{K} \sqrt{\mathrm{A} / \mathrm{tm}}}{\mathrm{A}}=\frac{\mathrm{K}}{\mathrm{Atm}}
$$

These formulas for the error of the mean may be rewritten:

9. Crumpler and Yoe, op. cit., p. 183. 


$$
\mathrm{y}_{\mathrm{m}}=\frac{\mathrm{K} \sqrt{\mathrm{A} / \mathrm{t}}}{\mathrm{m}}
$$

and

$$
\mathrm{F}_{\mathrm{m}}=\frac{\mathrm{K} / \sqrt{\mathrm{At}}}{\mathrm{m}}
$$

Thus the error of the mean of a series of similar counting rate determinations is numerically equal to the error of a single determination divided by the square root of the number of determinations.

In practice it is possible to calculate the error in the mean of a series of similar counting rate determinations by dividing the error of a single determination, calculated by use of Figures 3, 4, or 5, by the square root of the number of determinations.

\section{EXXMPIE}

Four similar experiments were performed and two-minute counting rate determinations were made of each of the samples prepared. The average of the four determinations was 2250 counts per minute. What is the $0.95 \%$ error of the final experimental result? The $0.95 \%$ error of a single twominute determination on a sample averaging 2250 counts per minute is found, from Figure 3, to be $2.9 \%$. The $0.95 \%$ error of the mean of four determinations would then be

$$
2.9 \% /(4)^{1 / 2}=2.9 \% / 2=1.5 \%
$$

THE ERROR IN A RESUIT COINPUTED HROM ANY FUNCTION OF DIRECTLY MEASURED QUANTITIES

In many cases involving the error of an indirectly determined result, the function may be more complex than either, simple addition, subtraction, multiplication or division and thus not computable by the methods described for these simple cases. The more complicated cases include those involving powers and roots, trancendental functions, and complex numbers. The error of a result computed from any function of directly measured quantities can be calculated if each of the errors in the directly measured quantities is known or can be estimated and has been shown 10 to be

$$
u=\sqrt{\left(\frac{\partial U}{\partial W}\right)^{2} W^{2}+\left(\frac{\partial U}{\partial X}\right)^{2} x^{2}+\left(\frac{\partial U}{\partial Y}\right)^{2} y^{2}+. .}
$$

where $U$ is any function calculated from the directly measured quantities $\mathrm{W}, \mathrm{X}, \mathrm{Y}, \mathrm{Z}$, etc., and $\mathrm{w}, \mathrm{X}, \mathrm{Y}, \mathrm{z}$, etc., are the respective errors in each of the directly measured quantities.

10. Crumpler and Yoe, op. cit., pp. 174-184. Worthing and Geffner, op. cit., pp. 205-214. 


\section{EXAMPIE}

The following formula is used to correct for coincidence losses in radioactive counting:

$$
\mathrm{T}=\mathrm{N}+\mathrm{CN}^{2}
$$

$C$ is the factor used to correct the observed rate $N$ to the true counting rate of the sample $T$.

Then

$$
\frac{\partial \mathrm{T}}{\partial \mathrm{N}}=1+2 \mathrm{CN}
$$

and

$$
\frac{\partial T}{\partial C}=N^{2}
$$

Therefore, the error in $\mathrm{T}$ is

$$
t=\sqrt{(1+2 \mathrm{CN})^{2} \mathrm{n}^{2}+\left(\mathrm{N}^{2}\right)^{2} \mathrm{c}^{2}}
$$

where $\mathrm{n}$ is the error in $\mathrm{N}$ and $\mathrm{c}$ is the error in $\mathrm{C}$.

If $\mathrm{C}$ is equal to $1.5 \times 10^{-5}$ with a 0.9 error of $5 \%$ and a 7500 count per minute sample is counted for two minutes, what is the per cent 0.9 error of the calculated true rate?

$$
\begin{aligned}
(1+2 \mathrm{CN})^{2} & =\left(1+2 \times 1.5 \times 10^{-5} \times 7500\right)^{2}=1.225^{2}=1.50 \\
\mathrm{~N}^{4} & =7500^{4}=3.164 \times 10^{15} \\
\mathrm{e}^{2} & =\left(0.05 \times 1.5 \times 10^{-5}\right)^{2}=\left(7.5 \times 10^{-7}\right)^{2}=56.05 \times 10^{-14} \\
\mathrm{n}^{2} & =(100.7)^{2}=10,147.5 \quad(\text { determined from Figure } 4) \\
t & =\sqrt{1.50 \times 10,147.5+3.164 \times 10^{15} \times 56.05 \times 10^{-14}} \\
\mathrm{t} & =\sqrt{15,221+1773}=\sqrt{16994}=130.5 \text { counts per minute } \\
\mathrm{T} & =7500\left(1+7500 \times 1.5 \times 10^{-5}\right)=7500(1.1125)=8343.75
\end{aligned}
$$

Per cent 0.9 Error in $\mathrm{T}=\frac{130.5}{8343.75} \times 100=1.56 \%$

MINIMIZING THE ERROR INTRODUCED BY THE BACKGROUND BY THE EFFICIENT DISTRIBUTION OF COUNTING TIME

We have shown that the presence of a background count increases the error, $\mathrm{y}$, of a counting rate determination $\left(\mathrm{N}_{\mathrm{S}}-\mathrm{N}_{\mathrm{b}}\right)$ as shown by the relation 


$$
\mathrm{y}=\left(\mathrm{QN}_{\mathrm{S}}^{2}+\mathrm{QNb}\right)^{1 / 2}=\mathrm{K}\left(\mathrm{N}_{\mathrm{S}} / \mathrm{t}_{\mathrm{S}}+\mathrm{N}_{\mathrm{b}} / \mathrm{t}_{\mathrm{b}}\right)^{1 / 2}
$$

where $N_{S}$ and $t_{S}$ refer to the counting rate of the sample and the sample counting time respectively and $N_{b}$ and $t_{b}$ refer to the counting rate of the background and the background counting time, respectively.

It is obvious there is not much advantage in counting the background for a long period of time in order to reduce the counting error, if the bulk of the error is due to the error in the determination of the sample. In this section we plan to show that when the total counting time is properly distributed between counting the sample and counting the background, the error will be amaller than for any other distribution of the total counting time. Conversely, the total counting time necessary to reduce the error to any given value, will be a minimum if the counting times of the sample and background are distributed properly.

The problem is, therefore, given the counting rates of the sample and background and the total counting time, to distribute the total counting time so that the error, $\mathrm{y}$, of the counting determination $\left(\mathbb{N}_{\mathrm{S}^{-}}\right.$ $N_{b}$ ) will be smaller than for any other distribution of the total counting time.

If we let $I$ be the total counting time $t_{s}+t_{b}$, then the error, $y$, will be a minimum when

$$
\frac{\mathrm{dy}}{\mathrm{dt}_{\mathrm{S}}}=0
$$

$$
\text { Since } t_{b}=L-t_{S}
$$

then

$$
\begin{aligned}
\frac{d y}{d t_{S}} & =\frac{d}{d t_{S}} K\left(\frac{N_{S}}{t_{S}}+\frac{N_{b}}{L-t_{S}}\right)^{1 / 2} \\
& =K \frac{\left(\frac{N_{b}}{t_{b}^{2}}-\frac{N_{S}}{t_{S}^{2}}\right)}{\left(\frac{N_{S}}{t_{S}}+\frac{N_{b}}{t_{b}}\right)}
\end{aligned}
$$

Thus $y$ will be a minimum when

or

$$
\begin{aligned}
& \frac{N_{b}}{t_{b}^{2}}-\frac{N_{S}}{t_{S}^{2}}=0 \\
& \frac{t_{S}}{t_{b}}=\left(\frac{N_{S}}{N_{b}}\right)^{1 / 2}
\end{aligned}
$$

The most efficient distribution of the total counting time between the sample and the background, in order to minimize the error introduced. by the background, is that in which the ratio of the counting times of the sample and the background is equal tn the square root of the ratio of the average counting rates of the sample and the background.

Figures 10 and 11 have been prepared to facilitate the counting time calculations in minimizing the background error. 


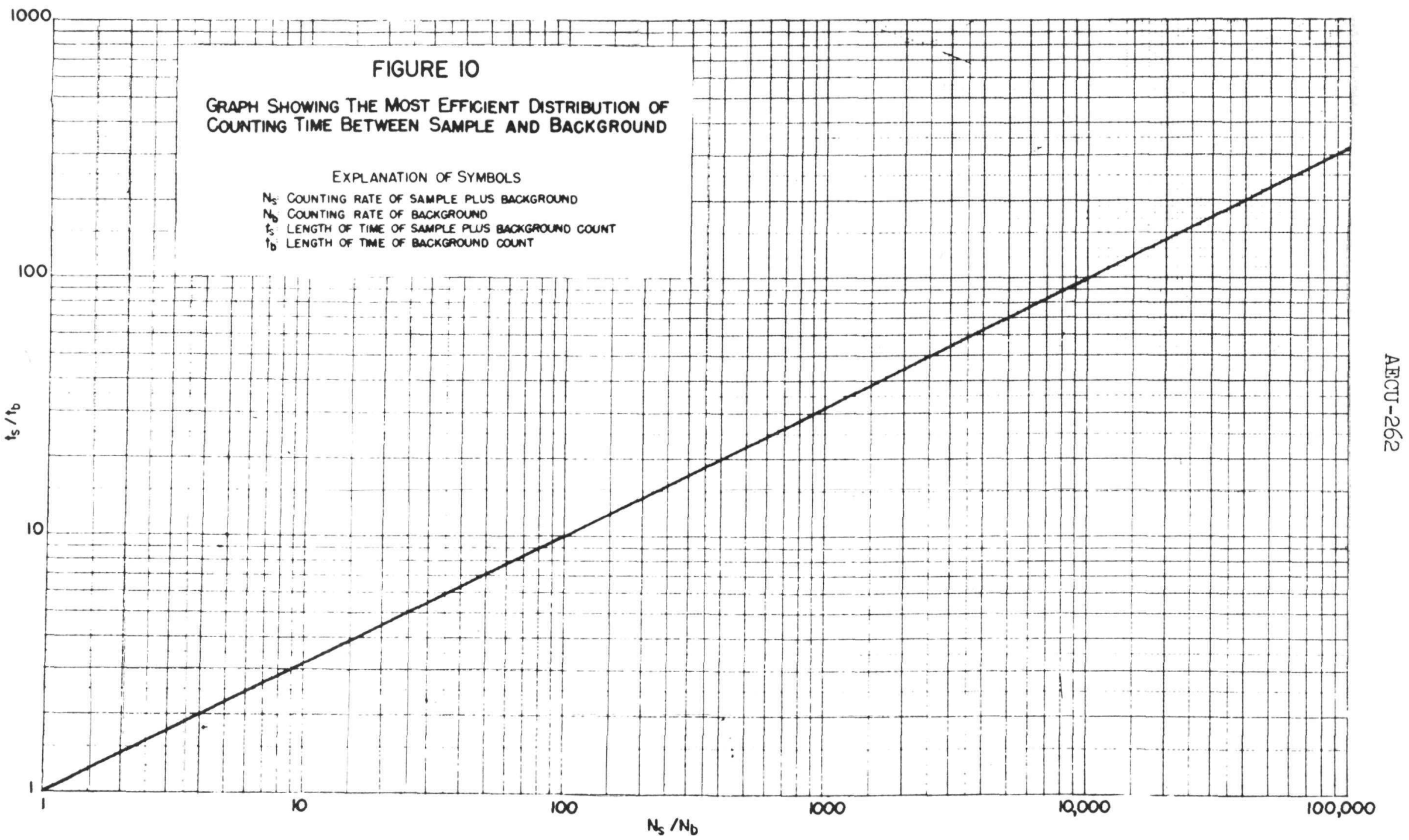


SAMPLE

COUNTING RATE

BACKGROUND

$=10,000$

COUNTING RAT

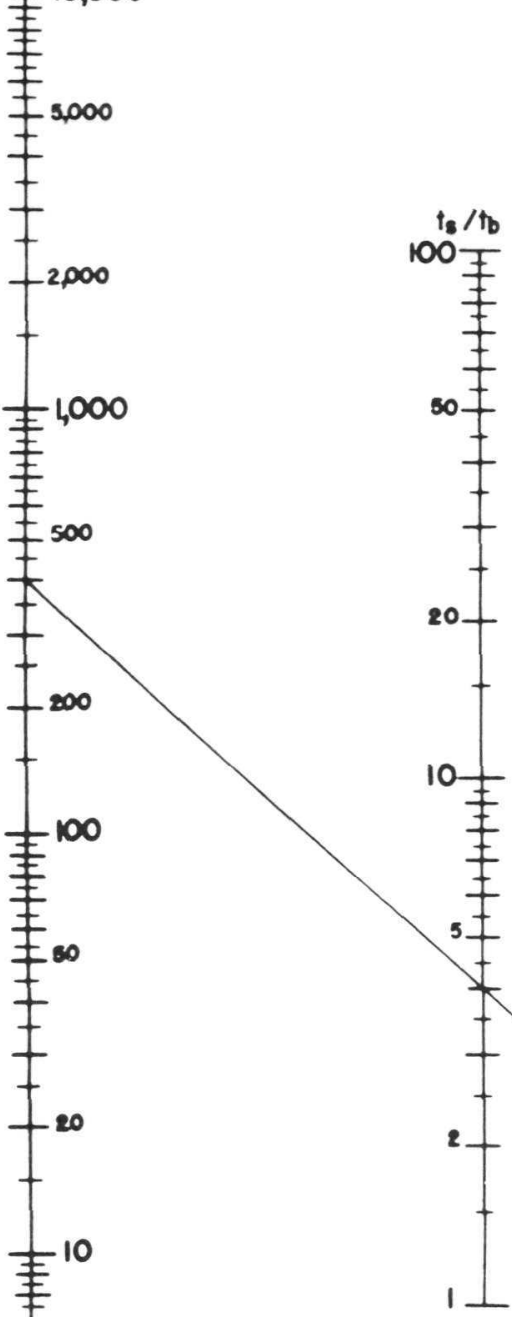

FIGURE II

NOMOGRAPH SHOWING THE MOST

EFFIGIENT DISTRIBUTION OF SAMPLE aNo BACKGROUNO COUNTING TIMES

\section{INSTRUCTIONS FOR USE}

Draw a straight line from a point on the left scale corresponding to the counting rate of the sample through the point on the right scale corresponding to the counting rate of the background. The point where this line crosses the center scale corresponds to the ratio of the counting times of the sample and the background necessary for maximum counting efficiency.

Example:

If the approximate counting rate of a sample, including the background, is 400 counts per minute and the background is roughly 25 counts per minute, the sample should be counted four times as long as the background for the maximum counting efficiency. If the total time were to be limited to 20 minutes 


\section{EXAMPIE}

The approximate counting rate of a sample, including the background, is 400 counts per minute and this background is roughly 25 counts per minute. From the nomograph of Figure 11 we see that the sample should be counted four times as long as the background for the maximum counting efficiency. If the total time were to be limited to 20 minutes of counting, the sample should be counted for 16 minutes and the background counted for 4 minutes in order to realize the minimum error in 20 minutes of counting time.

\section{THE DETERMINATION OF NON-STATISTICAL COUNTER BEHAVIOR}

In addition to the fluctuation expected in the counting rate of a radioactive sample due to the random nature of the disintegration process, there are other variables affecting the counting rate which tend to increase the actual error made in a counting determination. The significance of any unusual variations can be approximated by comparing the distribution of a series of counting determinations made on the same sample, with the dispersion expected if the apparatus were counting in a manner predicted by the law of random disintegration. This is done by a procedure which can be summarized into three general steps:

1. Set up the hypothesis that the distribution observed might occur because of chance factors arising from the random nature of the disintegration process.

2. Upon the basis of this hypothesis, determine the probability that the distribution which occurred might occur because of real variations in the disintegration rate alone.

3. Draw a conclusion concerming the reasonableness of the hypothesis. If such an observed distribution could often occur because of chance, we have cast very little doubt upon the hypothesis. We, therefore, continue to regard the hypothesis as tenable and conclude that the variations are not significant. If, however, such a distribution could hardly have occurred by chance, we have cast doubt upon the hypothesis. We, therefore, abandon the hypothesis, conclude that the variations are significant and try to determine the magnitude and the causes of the unusual portion of the variations.

Just how small the probability must be that the distribution could have occurred by chance variations in the decay rate, has been discussed previously. As before, if the probability is below 0.I, there is some doubt that the distribution is statistical; if it is less than 0.05, the variations are probably greater than would be satisfactory; and if the probability is less than 0.01 , it is quite certain that the distribution contains variations which are due to causes other than the random nature of the disintegration process.

This section of the report intends to describe two procedures whereby distribution abnormalities may be revealed. In a subsequent report we will describe some statistical procedures for evaluating the actual magnitude of the unusual variations. These methods are not applicable if less than ten counts are recorded in any of the determinations and are most significant when applied to determinations of more than thirty recorded counts. 
The first method consists of determining the value of the standard error of the difference between two counting determinations on the same sample or similar samples and comparing this with the observed difference between the two determinations. The standard error of the difference is given by the formula developed in a preceding section:

$$
y=\sqrt{\frac{N_{1}}{t_{1}}+\frac{N_{2}}{t_{2}}}
$$

Having now the two values: (1) The observed difference between the two determinations, $\mathbb{N}_{1}-N_{2}$, and (2) the standard error of the difference between the two determinations, we are in a position to answer the question: If the variations in the counting rate are only due to the randomness of the disintengration process, what is the probability that $\mathbb{N}_{I}$ might exceed $\mathbb{N}_{2}$ by the observed difference or more, because of chance variations?

This probability can be detemined by calculating the ratio of the observed difference to the standard error of the difference, $N_{I}-N_{2} / Y$, and finding the probability either in Table IV or Figure 12.11

Table IV--Probability of Observing $\left(\mathbb{N}_{1}-\mathbb{N}_{2}\right) / y$

Equal to or Greater than p.

(Values of $p$ less than 1.00 are not in this table because they have very little significance statistically)

\begin{tabular}{cccccccc}
\hline$p$ & $p$ & $p$ & $p$ & $p$ & $p$ & $p$ & $p$ \\
\hline 1.0 & 0.159 & 2.0 & 0.023 & 3.0 & 0.00135 & 4.0 & 0.0000317 \\
1.1 & 0.136 & 2.1 & 0.018 & 3.1 & 0.00097 & 4.1 & 0.0000207 \\
1.2 & 0.115 & 2.2 & 0.014 & 3.2 & 0.00068 & 4.2 & 0.0000133 \\
1.3 & 0.097 & 2.3 & 0.011 & 3.3 & 0.00048 & 4.3 & 0.0000085 \\
1.4 & 0.081 & 2.4 & 0.008 & 3.4 & 0.00034 & 4.4 & 0.0000054 \\
1.5 & 0.067 & 2.5 & 0.006 & 3.5 & 0.00023 & 4.5 & 0.0000034 \\
1.6 & 0.055 & 2.6 & 0.005 & 3.6 & 0.00016 & 4.6 & 0.0000021 \\
1.7 & 0.045 & 2.7 & 0.003 & 3.7 & 0.00011 & 4.7 & 0.0000013 \\
1.8 & 0.036 & 2.8 & 0.003 & 3.8 & 0.00007 & 4.8 & 0.0000008 \\
1.9 & 0.020 & 2.9 & 0.002 & 3.9 & 0.00005 & 4.9 & 0.0000005 \\
\hline
\end{tabular}

\section{EXAMP LE}

A long-lived sample was counted for 4 minutes at the beginning of an experiment and averaged 5925 counts per minute. After the experiment

11. A more detailed discussion of this method of analysis, its limitations and implications and one which also describes the basis on which Table IV and Figure 12 were prepared, is given in Croxton and Cowden, op. cit., pp. 317-322.

Peters and Van Voorhis, op. cit., pp. 169-170 and Crumpler and Yoe, op. cit., pp. 186-188 also give good interpretations of statistically reliable differences. 
was concluded, the same sample was counted as a check and averaged 6075 counts per minute in a two-minute determination. Is this amount of variation indicative of a poor instrument or is the difference perhaps due to chance variations in the disintegration rate?

$$
\begin{aligned}
& \mathrm{y}=\sqrt{\frac{5925}{4}+\frac{6075}{2}}=68 \text { counts per minute } \\
& \mathrm{p}=\frac{\mathrm{N}_{1}-\mathrm{N}_{2}}{\mathrm{y}}=\frac{6075-8925}{68}=\frac{150}{68}=2.2
\end{aligned}
$$

From Table IV we can see that for p equals 2.2, the probability of observing a difference as large as or larger than 150 counts per minute is 0.014 .

Thus there are only 14 chances out of a 1000 that this particular dispersion will occur. In accordance with our arbitrary standards of significance, this is not sufficient to unequivocably conclude that the instrument is behaving improperly, but it is a strong indication that this is the case. Here is a rapid, easy to use test of only two determinations which reveals significant information regarding the accuracy of a counting rate determination.

A more rigid test which investigates the dispersion of two or more similar determinations and which may be used to more conclusively evaluate the significance of unusual counting determination variations is called the chi-square test of variation. This test is particularly useful for investigating instrument behavior when 20 or more determinations are taken in investigating the quality of the instrument.

The chi-square test is useful for determining whether or not a given series of counting determinations on the same sample can be reasonably supposed to have arisen from random variations of disintegration. This test is often called the test of goodness of fit. A complete derivation and discussion of the aspects of the chi-square distribution is given by Peters and Van Voorhis and others. 12 It is shown that for true sample of a Poisson series, chi-square, defined by the relation

$$
x_{n}^{2}=\frac{\left(N_{1}-A v \cdot\right)^{2}+\left(N_{2}-A v \cdot\right)^{2}+\cdot \cdot+(N m-A v \cdot)^{2}}{(A v \cdot / t)}
$$

Will be distributed in a known manner. This distribution depends only upcn the number of determinations of the counting rate used in the calculation of chi-squared and is independent of the actual counting rate.

Having calculated the value of chi-squared corresponding to a given number of determinations, it is possible to determine the probability that the observed distribution is a reasonable one to expect if the variations are only due to the randomness of the disintegration process. This probability has been calculated as a function of chi-squared and the number of determinations and is shown in Table $\mathrm{V}$ and also on the

12. Peters and Van Voorhis, op. cit., pp. 404-414, p. 419. Fisher, op. cit., p. 58, 00. 78-85. Worthing and Geffner, op. cit., pp. 183-186. Fry, op. cit., pp. 265-320. 


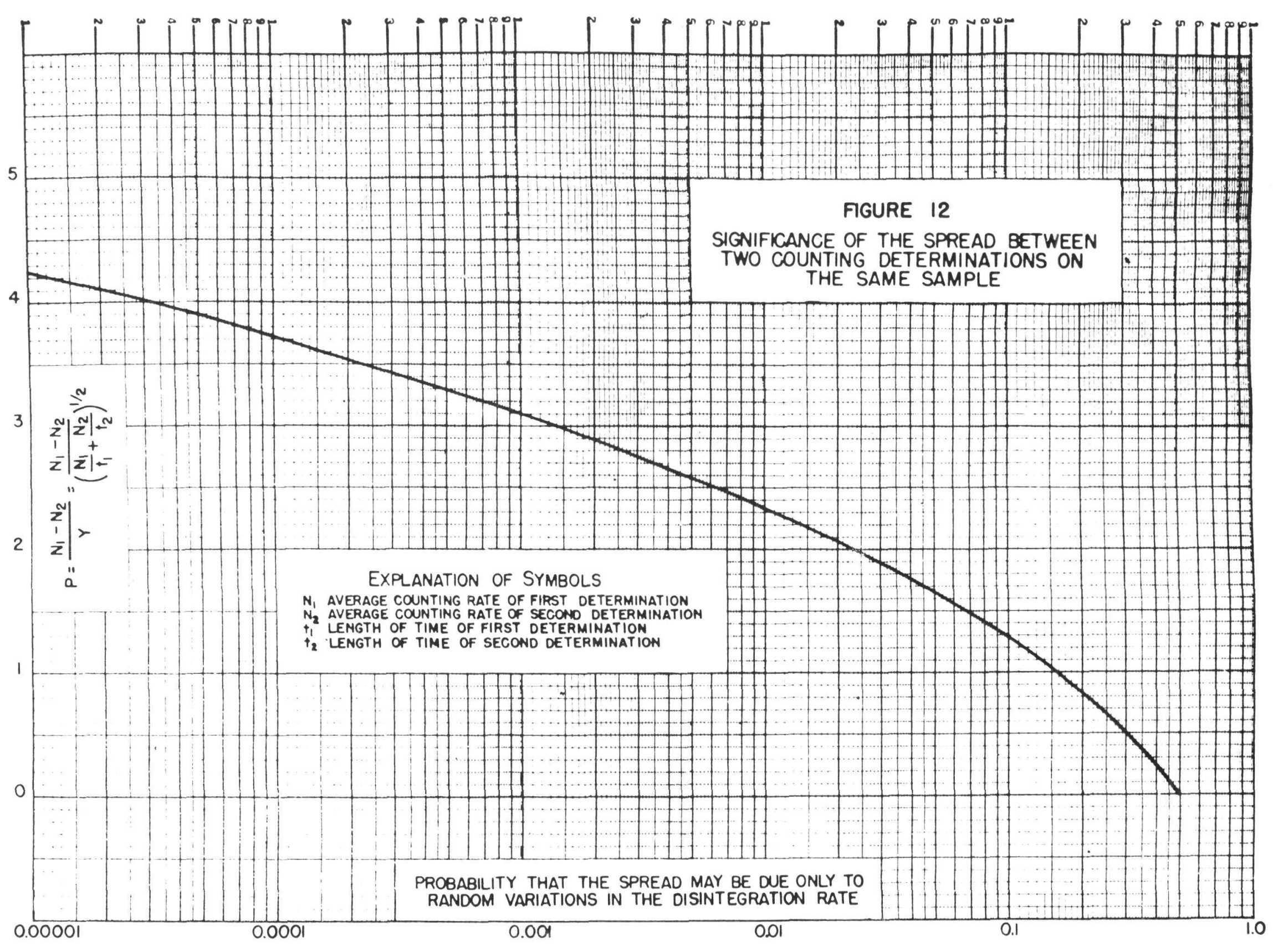


graph of Figure 13. More complete tables of this distribution may be found in the literature.13

If the probability is greater than 0.1 there is certainly no reason to suspect that the distribution is any poorer than could be obtained under the most satisfactory operating conditions. The significance of probabilities less than 0.1 have been discussed previously and also apply to the problem at hand. It is to be emphasized that high values of the probability (above 0.9) corresponding to low values of chi-squared are to be regarded as definitely indicative of a poor determination as low values of the probability due to abnormally high values of chi-squared. It is recommended that 20 determinations on the same sample be the minimum number necessary for an exhaustive analysis of counter behavior. 14

\section{EXAMPLE}

Ten two-minute determinations of the counting rate of the same sample are tabulated below. Would the instrument be considered as behaving properly?

$$
\begin{array}{lllll}
6064 & 5964 & 5980 & 6020 & 5887 \\
6018 & 6064 & 6078 & 6094 & 5984
\end{array}
$$

The average counting rate is calculated by summing the counting rates of each determination and dividing by the number of determinations and is thus found to be 6015 counts per minute. The average is subtracted from each of the determinations and the result squared. I5 The sum of the squares of the deviations from the average has been calculated to be 36016. In accordance with the chi-squared formula

$$
\chi_{10}^{2}=\frac{36016}{6015 / 2}=12.0
$$

From Table $V$ we find that the probability of obtaining a chi-squared equal to 12.0 for 10 determinations is less than 0.9 and more than 0.1 and thus this distribution is reasonably Poissonian and therefore the instrument could be assumed to be operating properly.

13. Fisher, op. cit., pp. 112-113.

Blair, op. cit., p. 491.

Croxton and Cowden, op. cit., p. 882.

Fry, op. cit., pp. 468-469.

Peters and Van Voorhis, op. cit., pp. 498-500.

14. Similar tests of counter statistics are described by: Coveyou, Testing of Counter-scales Units for Statistics, Private Communication. 1946, p. 154 . Korff, Electron and Nuclear Counters, Van Nostrand, New York, Strong, Procedures in Experimental Physics, Prentice-Hall, New York, 1943, pp. 302-304.

15. If a Friden calculating machine is available, the sum of the squares of the deviations from the average may be more quickly calculated using the easily derived formula.

$$
\left(N_{1}-A V\right)^{2}+\left(N_{2}-A v\right)^{2}+\ldots .+\left(N_{m}-A v\right)^{2}=N^{2}-m(A v)^{2}
$$




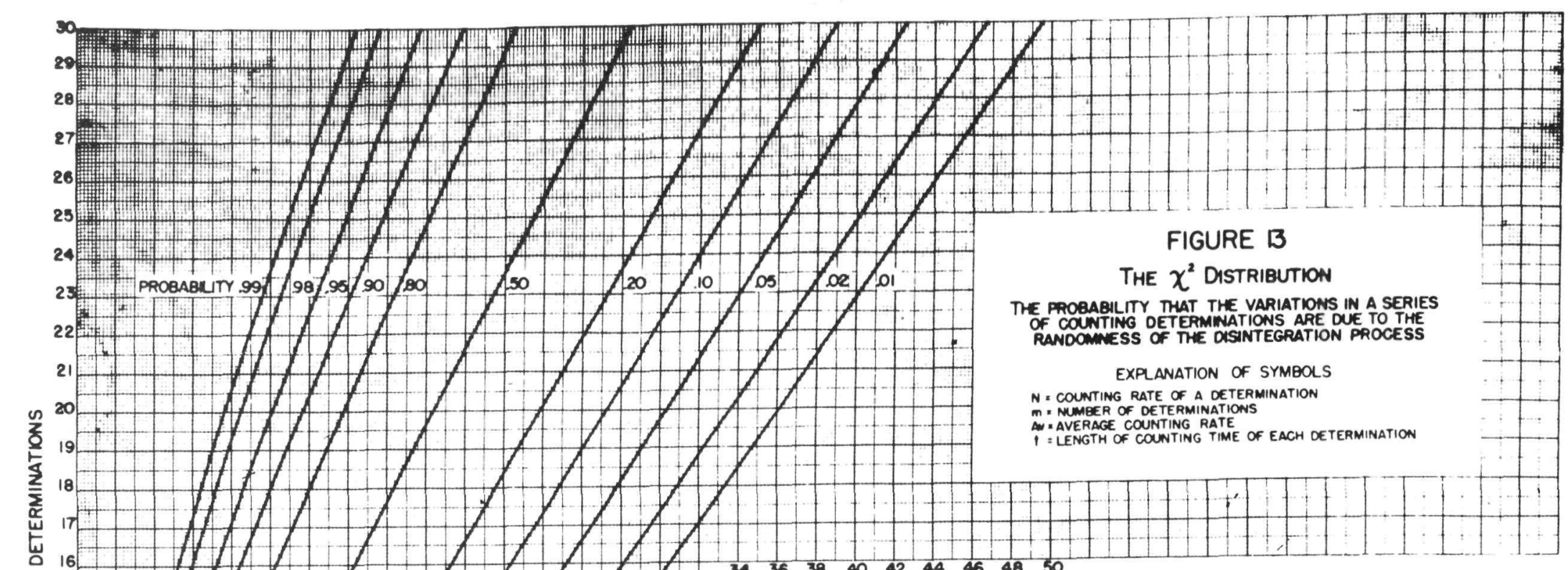

$16+11$

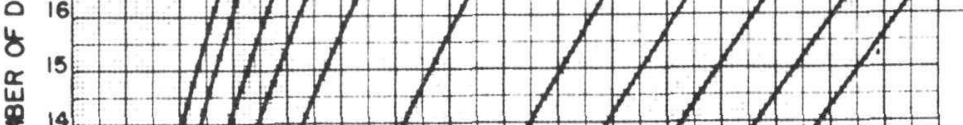

.

.

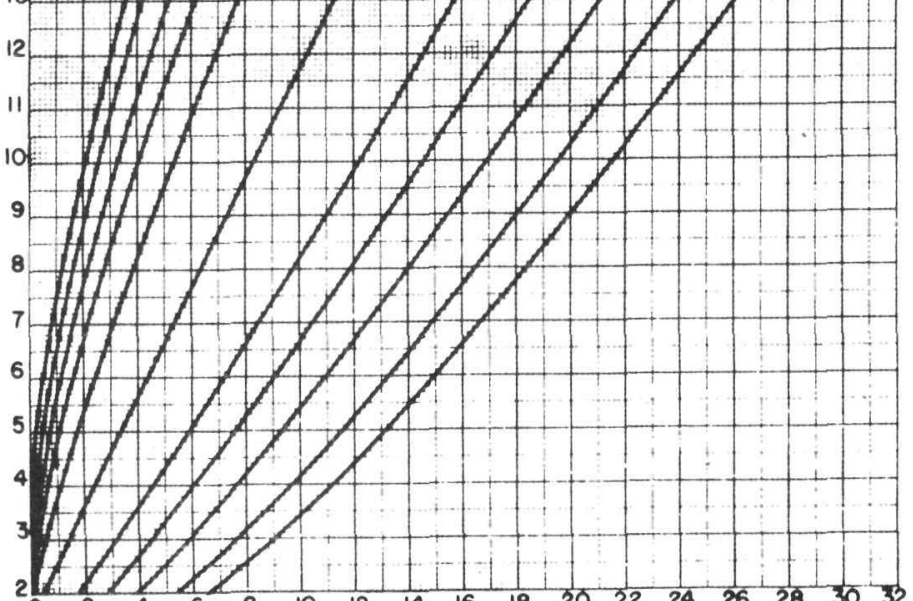

$\chi^{2}=\frac{\left(N_{1}-A V V^{2}+\left(N_{2}-A V\right)^{2}+\cdots+\left(N_{m}-A V\right)^{2}\right.}{A V(1)}$

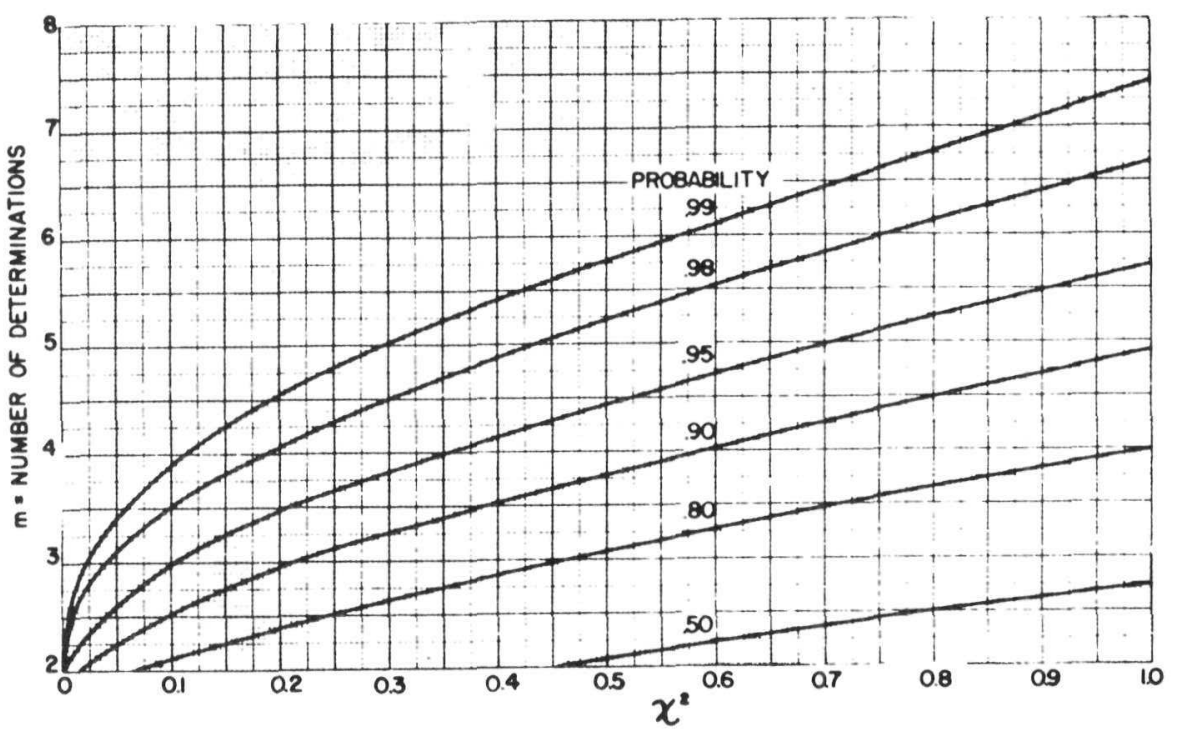


Table V--Table of Chi-squared

Number of

Determinations

Probability

\begin{tabular}{|c|c|c|c|c|c|c|c|}
\hline & 0.99 & 0.95 & 0.90 & 0.50 & 0.10 & 0.05 & 0.01 \\
\hline $\begin{array}{l}2 \\
3 \\
4 \\
5\end{array}$ & $\begin{array}{l}0.00157 \\
0.0201 \\
0.115 \\
0.297\end{array}$ & $\begin{array}{l}0.00393 \\
0.103 \\
0.352 \\
0.711\end{array}$ & $\begin{array}{l}0.0158 \\
0.211 \\
0.584 \\
1.064\end{array}$ & $\begin{array}{l}0.455 \\
1.386 \\
2.366 \\
3.357\end{array}$ & $\begin{array}{l}2.706 \\
4.605 \\
6.251 \\
7.779\end{array}$ & $\begin{array}{l}3.841 \\
5.991 \\
7.815 \\
9.488\end{array}$ & $\begin{array}{r}6.635 \\
9.210 \\
11.345 \\
13.277\end{array}$ \\
\hline $\begin{array}{r}6 \\
7 \\
8 \\
9 \\
10\end{array}$ & $\begin{array}{l}0.554 \\
0.872 \\
1.239 \\
1.646 \\
2.088\end{array}$ & $\begin{array}{l}1.145 \\
1.635 \\
2.167 \\
2.733 \\
3.325\end{array}$ & $\begin{array}{l}1.610 \\
2.204 \\
2.833 \\
3.490 \\
4.168\end{array}$ & $\begin{array}{l}4.351 \\
5.348 \\
6.346 \\
7.344 \\
8.343\end{array}$ & $\begin{array}{r}9.236 \\
.10 .645 \\
12.017 \\
13.362 \\
14.684\end{array}$ & $\begin{array}{l}11.070 \\
12.592 \\
14.067 \\
15.507 \\
16.919\end{array}$ & $\begin{array}{l}15.086 \\
16.812 \\
18.475 \\
20.090 \\
21.666\end{array}$ \\
\hline $\begin{array}{l}11 \\
12 \\
13 \\
14 \\
15\end{array}$ & $\begin{array}{l}2.558 \\
3.053 \\
3.571 \\
4.107 \\
4.660\end{array}$ & $\begin{array}{l}3.940 \\
4.575 \\
5.226 \\
5.892 \\
6.571\end{array}$ & $\begin{array}{l}4.865 \\
5.578 \\
6.304 \\
7.042 \\
7.790\end{array}$ & $\begin{array}{r}9.342 \\
10.341 \\
11.340 \\
12.340 \\
13.339\end{array}$ & $\begin{array}{l}15.987 \\
17.275 \\
18.549 \\
19.812 \\
21.064\end{array}$ & $\begin{array}{l}18.307 \\
19.675 \\
21.026 \\
22.362 \\
23.685\end{array}$ & $\begin{array}{l}23.209 \\
24.725 \\
26.217 \\
27.688 \\
29.141\end{array}$ \\
\hline $\begin{array}{l}16 \\
17 \\
18 \\
19 \\
20\end{array}$ & $\begin{array}{l}5.229 \\
5.812 \\
6.408 \\
7.015 \\
7.633\end{array}$ & $\begin{array}{r}7.261 \\
7.962 \\
8.672 \\
9.390 \\
10.117\end{array}$ & $\begin{array}{r}8.547 \\
9.312 \\
10.085 \\
10.865 \\
11.651\end{array}$ & $\begin{array}{l}14.339 \\
15.338 \\
16.338 \\
17.338 \\
18.338\end{array}$ & $\begin{array}{l}22.307 \\
23.542 \\
24.769 \\
25.989 \\
27.204\end{array}$ & $\begin{array}{l}24.996 \\
26.296 \\
27.587 \\
28.869 \\
30.144\end{array}$ & $\begin{array}{l}30.578 \\
32.000 \\
33.409 \\
34.805 \\
36.191\end{array}$ \\
\hline $\begin{array}{l}21 \\
22 \\
23 \\
24 \\
25\end{array}$ & $\begin{array}{r}8.260 \\
8.897 \\
9.542 \\
10.196 \\
10.856\end{array}$ & $\begin{array}{l}10.851 \\
11.591 \\
12.338 \\
13.091 \\
13.848\end{array}$ & $\begin{array}{l}12.443 \\
13.240 \\
14.041 \\
14.848 \\
15.659\end{array}$ & $\begin{array}{l}19.337 \\
20.337 \\
21.337 \\
22.337 \\
23.337\end{array}$ & $\begin{array}{l}28.412 \\
29.615 \\
30.813 \\
32.007 \\
33.196\end{array}$ & $\begin{array}{l}31.410 \\
32.671 \\
33.924 \\
35.172 \\
36.415\end{array}$ & $\begin{array}{l}37.566 \\
38.932 \\
40.289 \\
41.638 \\
42.980\end{array}$ \\
\hline $\begin{array}{l}26 \\
27 \\
28 \\
29 \\
30\end{array}$ & $\begin{array}{l}11.524 \\
12.198 \\
12.879 \\
13.565 \\
14.256\end{array}$ & $\begin{array}{l}14.611 \\
15.379 \\
16.151 \\
16.928 \\
17.708\end{array}$ & $\begin{array}{l}16.473 \\
17.292 \\
18.114 \\
18.939 \\
19.768\end{array}$ & $\begin{array}{l}24.337 \\
25.336 \\
26.336 \\
27.336 \\
28.336\end{array}$ & $\begin{array}{l}34.382 \\
35.563 \\
36.741 \\
37.916 \\
39.087\end{array}$ & $\begin{array}{l}37.382 \\
38.885 \\
40.113 \\
41.337 \\
42.557\end{array}$ & $\begin{array}{l}44.314 \\
45.642 \\
46.963 \\
48.278 \\
49.588\end{array}$ \\
\hline
\end{tabular}


Occasionally, in a series of similar experiments, a result appears which differs considerably from the results of the group as a whole. The presence of this abnormal result does not necessarly indicate that a gross error has been made although this may be the explanation for the unusual deviation. If this divergent variation occurs as one of a serjes of a small number of determinations, its influence on the best value of the determination may be unduly large and it is reasonable to conclude that the average of the determination would be more representative of the correct answer if the determination were discarded in the calculation of the average. Although the measurement may be rejected if there is definite evidence of unusualness during the course of the determination of the unusual result, with no such evidence it is desirable, in the interest of accuracy, that the determination be rejected and thus a criterion of rejection is necessary.

Such a criterion has been developed and is described in the literature. 16 In words, this criterion states that any reading of a series of $\mathrm{n}$ readings shall be rejected when the magnitude of its deviation from the mean of the series is such that the probability of occurrence of all deviation that large or larger is less than 1/2n. Table VI and Figure 14 indicate the magnitude of this deviation in terms of multiples of the standard deviation as a function of various values of $n$.

Table IV--Chauvenet's Criterion of the Rejection of Suspected Observations

Limiting values of the deviation of a reading from the mean of a series in terms of multiples of the standard deviation, for the exclusion of that reading from the series on the basis that, in comparison with the other items, it exerts too great an influence on the average of the series.

$\mathrm{n}=$ number of determinations in the series

$\mathrm{p}=$ ratio of the deviation to the standard deviation

\begin{tabular}{rrrrrrrrrr}
\hline $\mathrm{n}$ & $\mathrm{p}$ & $\mathrm{n}$ & $\mathrm{p}$ & $\mathrm{n}$ & $\mathrm{p}$ & $\mathrm{n}$ & $\mathrm{p}$ & $\mathrm{n}$ & $\mathrm{p}$ \\
\hline 2 & 1.15 & 7 & 1.80 & 15 & 2.13 & 40 & 2.50 & 250 & 3.09 \\
3 & 1.38 & 8 & 1.86 & 20 & 2.24 & 50 & 2.58 & 300 & 3.14 \\
4 & 1.54 & 9 & 1.91 & 25 & 2.33 & 75 & 2.71 & 400 & 3.23 \\
5 & 1.65 & 10 & 1.96 & 30 & 2.40 & 100 & 2.81 & 500 & 3.29 \\
6 & 1.73 & 12 & 2.04 & 35 & 2.45 & 200 & 3.02 & 1000 & 3.48 \\
\hline
\end{tabular}

The criterion is used as follows:

1. Compute the mean and the standard deviation of a single observation, retaining all suspected observations in the computation.

2. Determine the ratio of the suspiciously large deviation to the standard deviation of a single observation.

16. Worthing and Geffner, op. cit., pp. 170-171. Crumpler and Yoe, op. cit., pp. 188-191. 
3. From Table VI or Figure 14 secure the limiting value of the ratio for the corresponding number of determinations, $n$.

4. If the observed ratio is greater than the value found on the graph or in the table, the observation may be rejected.

EXAMPLE

Five two-minute counting rate determinations were made on the same sample with the following results:

$$
2046 \quad 2105 \quad 2011 \quad 2072 \quad 2016
$$

Should the value 2105 be rejected?

The nean counting rate, including the suspected 2105, is 2050 counts per minute. The standard deviation, computed from the formula previously described is

$$
(2050 / 2)^{1 / 2}=32 \text { counts per minute }
$$

This value may also be determined from Figures 3 or 5 .

The ratio of the suspected deviation to the standard deviation is

$$
\frac{2105-2050}{32}=1.72
$$

For 5 determinations the tabulated value is 1.65. Because this is smaller than the ratio of the deviation to the standard deviation, the observation 2105 should be rejected. The best value for the experiment would then be the mean of the remaining four determinations which is 2036.

\section{BIBIIOGRAPHY}

Blair, Elementary Statistics, Holt, New York, 1944.

Croxton and Cowden, Applied General Statistics, Prentice-Hall, New York, 1944.

Crumpler and Yoe, Chemical Computations and Errors, Wiley, New York, 1940. Davis, Empirical Equations and Nomography, McGraw-Hill, New York, 1944. Fisher, Statistical Methods for Research Workers, Oliver and Boyd, London, 1944.

Fry, Probability and Its Engineering Uses, Van Nostrand, New York, 1928. Hodgman, Handbook of Chemistry and Physics. Chemical Rubber Publishing Co., Cleveland, Ohio, 1944.

Korff, Electron and Nuclear Counters, Van Nostrand, New York, 1946.

Lange, Handbook of Chemistry, Handbook Publishers Inc., Sandusky, Ohio, 1941.

Peters and Van Voorhis, Statistical Procedures and Their Mathematical Bases, McGraw-Hill, New York, 1940.

Rasetti, Elements of Nuclear Physics, Prentice-Hall, New York, 1936. Strong, Procedures in Experimental Physics, Prentice-Hall, 1943. Worthing and Geffner, Treatment of Experimental Data, Wiley, New York, 1944.

W.P.A., Tables of Probability Functions, Volume II, Washington, D. C., 3942. 


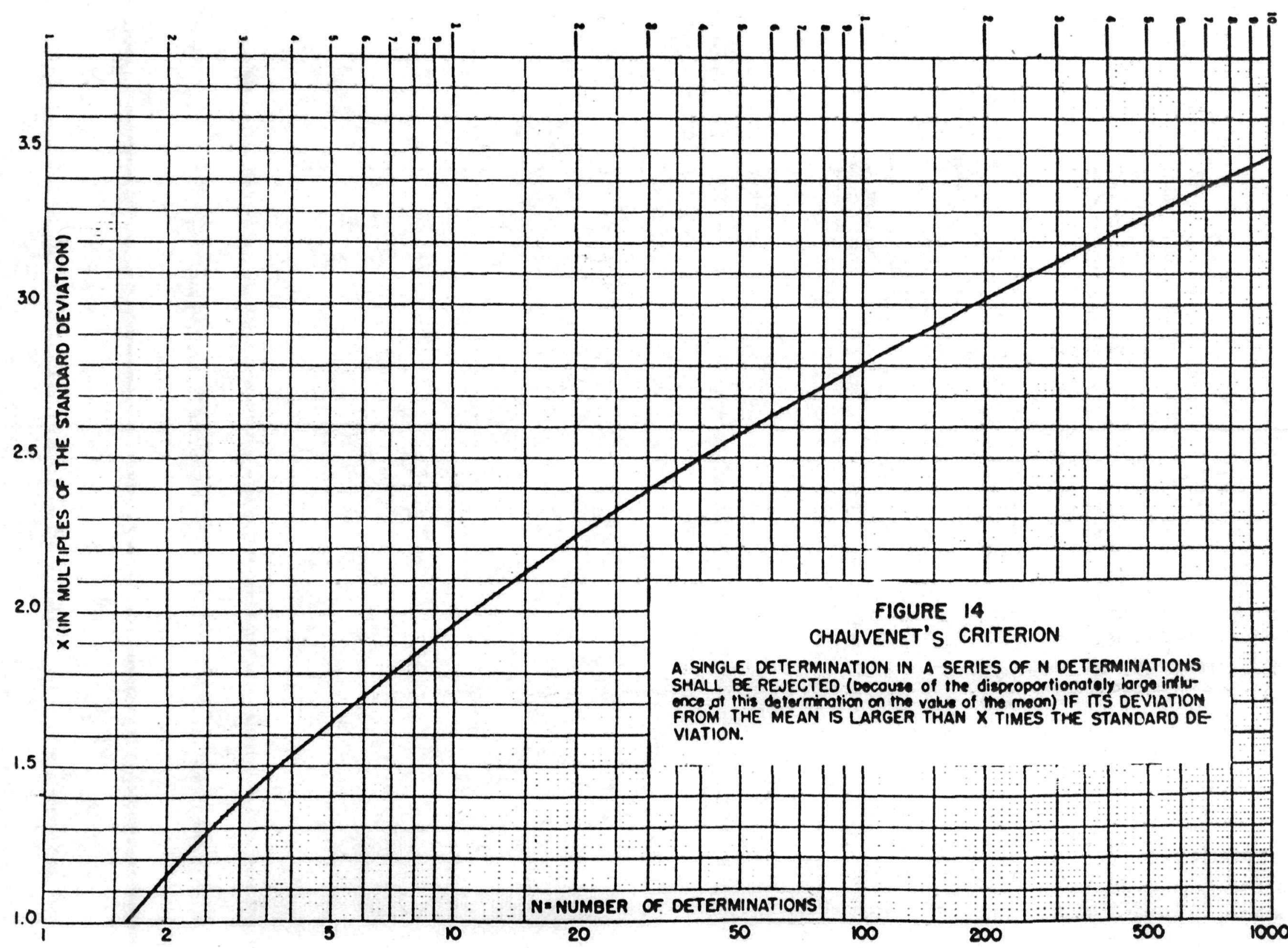

